\title{
MEJORA CONTINUA AL SISTEMA DE ASEGURAMIENTO DE LA CALIDAD DE LAS AUDITORÍAS INTERNAS
}

\section{CONTINUOUS IMPROVEMENT TO THE QUALITY ASSURANCE SYSTEM OF INTERNAL AUDITS}

\author{
Giovanni Solano-Cruz ${ }^{1}$ \\ Aprobado: 31/08/2021
}

\begin{abstract}
RESUMEN
Esta investigación tiene un enfoque cuantitativo y es tipo descriptivo. Se aplica a los auditores internos y personal técnico colaborador de 22 Unidades de Auditoría Interna gubernamentales, un cuestionario de 44 preguntas dividido en las tres variables que sustentan la investigación: metodología de las Unidades de Auditoría Interna para el aseguramiento de la calidad; aplicación del marco normativo y mejoras prácticas; $y$ fortalezas y debilidades de las Unidades de Auditoría Interna. Los resultados muestran que las auditorías internas están conformadas por personal que reúne los requisitos académicos y experiencia; sin embargo, se debe mejorar la calidad del trabajo, implementando recomendaciones como la medición y análisis de los indicadores de gestión, inclusión de auditorías operativas en el plan anual de trabajo, implementación de mejores prácticas mundiales, uso de herramientas tecnológicas, identificación de riesgos, capacitación profesional continua, adopción de un sistema de gestión de la calidad, etc.
\end{abstract}

PALABRAS CLAVE: AUDITORÍA, AUTOEVALUACIÓN, TECNOLOGÍA, ANÁLISIS DE DATOS, FORMACIÓN PROFESIONAL, SISTEMA DE INFORMACIÓN DE GESTIÓN, SECTOR PÚBLICO. CLASIFICACIÓN JEL: M420

\section{ABSTRACT}

This research has a quantitative focus and is descriptive. It was applied to internal auditors and collaborating technical personnel from 22 governmental internal auditing units. This research is comprised of a 44-question questionnaire divided in the three variables that underpin it: the methodology of the internal auditing units for assuring quality; the application of the normative framework and practical improvements; and the strengths and weaknesses of the internal auditing units. The results show that the internal audits are made up of personnel who meet the academic and experience requirements. However, work

1 Investigador independiente; Código Postal 10701; Mora, San José, Costa Rica; gsolanoc@yahoo.com 
quality must be improved, by implementing recommendations such as the measurement and analysis of key performance indicators, the inclusion of operational audits in the annual work plan, the implementation of global best practices, the use of technological tools, the identification of risks, the introduction of a quality management system, continuous professional capacity developments, etc.

KEYWORDS: AUDIT, SELF-ASSESSMENT, TECHNOLOGY, DATA ANALYSIS, PROFESSIONAL EDUCATION, MANAGEMENT INFORMATION SYSTEM, AND PUBLIC SECTOR.

JEL CLASSIFICATION: M420

\section{INTRODUCCIÓN}

Las unidades de auditorías internas del sector público, objeto de estudio de esta investigación, se ubican en instituciones de diferentes sectores con una variedad de actividades sustantivas que son reguladas por normativa nacional e internacional, con un presupuesto anual limitado. La investigación se realizó en el sector público no financiero y financiero, por lo tanto, el estudio abarca instituciones del Poder Ejecutivo como los bancos estatales, ministerios, museos, así como el sector universitario, salud, bomberos y el Poder Judicial, para una muestra total de 22 instituciones públicas ubicadas en la provincia de San José.

La investigación se desarrolló en el periodo comprendido de enero a diciembre de 2018. Esta abarca el análisis de la normativa relacionada al aseguramiento de la calidad emitida por la Contraloría General de la República y el Instituto de Auditores Internos Global, así como otras entidades que permitan mejorar la función de las auditorías internas.

Por último, es importante mencionar como limitación al alcance de la investigación, que no existe un centro de datos de todas las auditorías internas del sector público costarricense con información relevante de cada una, por ejemplo, informes de auditoría, oficios, reglamento de organización y funcionamiento, manuales y procedimientos, entre otros datos; aspectos de gran importancia para fortalecer las limitaciones y carencias de la administración pública, con el propósito de fortalecer estrategias y mecanismos para el aseguramiento de la calidad.

Adicionalmente, los resultados de la autoevaluación anual y evaluación externa de calidad de las auditorías internas no son remitidos a la Contraloría General de la República (CGR) para su publicación, como si se realiza con el índice de gestión institucional que se publica en la Memoria anual de la CGR.

A nivel nacional, el tema del aseguramiento de la calidad en la auditoría inicia con el Manual de normas para el ejercicio de la Auditoría Interna en el Sector Público (M-1-2004-CODDI), de la CGR (2004), el cual dispone en la norma 1.4 que el auditor interno debe desarrollar, aplicar, mantener y perfeccionar un programa de aseguramiento de la calidad que cubra todos los aspectos de la actividad de auditoría interna. Posteriormente, se emitieron las Directrices para la autoevaluación anual de calidad de las auditorías internas del Sector Público, D-2-2007-CO-DFOE de la CGR (2007), las cuales se derogan con la emisión de la D-2-2008-CO-DFOE de la CGR (2008).

Las Normas para el ejercicio de la auditoría interna en el Sector Público, resolución R-DC119-2009 de la CGR (2010) mencionan como parte de las normas sobre atributos, el aseguramiento de la calidad. Posteriormente la CGR (2014) publica las Normas Generales de Auditoría para el Sector Público, R-DC-064-2014, en la cual se aborda la calidad en la auditoría. Mediante oficio $\mathrm{N}^{\circ} 12959$ del 12 de setiembre de 2018, la CGR (2018c) publica el Manual de referencia para auditorías (MARPAI) versión 1.0, en el sitio de internet de la CGR.

A nivel internacional, la Organización Internacional de Entidades Fiscalizadoras Superiores (INTOSAI, 2008) emitió la ISSAI 40 Control de Calidad para la EFS. El propósito de esta norma internacional es asistir a las Entidades Fiscalizadoras Superiores (EFS) para establecer y mantener un sistema apropiado de control de calidad que cubra todo el trabajo que estas entidades realizan. 
Adicional al INTOSAI, el Instituto de Auditores Internos (IAI) emitió las Normas Internacionales para el ejercicio profesional de la Auditoría Interna, el cual incorpora aspectos relacionados al aseguramiento de la calidad.

El sistema de aseguramiento de la calidad de las Unidades de Auditoría Interna (UAI) debe actualizarse aplicando la normativa nacional emitida por la Contraloría General de la República (CGR) y las mejores prácticas desarrolladas por el Instituto de Auditores Internos Global (IIA), Federación Internacional de Contadores, así como la Organización Internacional de Entidades de Fiscalización Superior (INTOSAI por sus siglas en inglés), entre otros. Si bien la metodología utilizada por las UAI considera las herramientas propuestas por la CGR, existe la interrogante sobre los resultados de la evaluación de calidad y el efecto positivo que puede generar en los diferentes procesos de la institución pública. A partir del año 2011, la CGR contacta a las UAI para propiciar la conformación de fuerzas de trabajo compartido, con la finalidad de investigar, mediante un esfuerzo colaborativo, temas específicos de interés de las UAI, la Administración activa y la CGR, para el fortalecimiento de esos tres componentes. Por lo tanto, dado el escenario y las condiciones actuales en las que se desenvuelven las UAI y su afán por cumplir con la normativa vigente de la CGR, específicamente el tema de aseguramiento de calidad, se realiza un análisis de la metodología que aplican las UAI para autoevaluarse y si los resultados obtenidos contribuyen a mejorar los productos de auditoría. De acuerdo con lo anterior, la pregunta principal de la investigación es la siguiente: ¿de qué manera están abordando el aseguramiento de la calidad en las UAI del sector público, en función del marco normativo y sus lineamientos? De la cual se desprenden las preguntas secundarias que se detallan a continuación: ¿cuál es la metodología empleada por las UAI del sector público, para el aseguramiento de la calidad del proceso de auditoría y sus productos?; ¿cuál es el marco normativo vigente $y$ las mejores prácticas mundiales, relacionados con el aseguramiento de la calidad de las Unidades de Auditoría Interna? y 3) ¿cuáles son las fortalezas y debilidades de las UAI del sector gubernamental con respecto al aseguramiento de calidad de sus procesos y productos?

Esto conduce al objetivo general "Analizar el Sistema de Aseguramiento de la Calidad de las Unidades de Auditoría Interna del sector público costarricense, en función del marco normativo y sus lineamientos, con el fin de contribuir al mejoramiento de la gestión de estas unidades fiscalizadoras" y específicos que seguidamente se enumeran:

1. Determinar la metodología empleada por las Unidades de Auditoría Interna del sector público, para el aseguramiento de la calidad del proceso de auditoría y sus productos.

2. Describir la aplicación del marco normativo vigente y las mejores prácticas mundiales en la metodología empleada por las Unidades de Auditoría Interna del sector público, para el aseguramiento de la calidad.

3. Evaluar las fortalezas y debilidades de las prácticas procedimentales de las UAI del sector público en búsqueda de la calidad.

La fundamentación teórica de la investigación incorpora aspectos generales del aseguramiento de la calidad y de las UAI del sector gubernamental costarricense.

\section{Aseguramiento de la calidad}

Para que el proceso de auditoría mantenga sus labores de manera eficiente y efectiva, debe considerarse al aseguramiento de la calidad, como un elemento de apoyo indispensable y permanente en las actividades de planificación, ejecución, comunicación y seguimiento. Asimismo, se garantiza la calidad del trabajo, mejorando la imagen de la UAI en la institución y la sociedad. El aseguramiento de la calidad se aborda por la INTOSAI, en la norma ISSAI 40 Control de 
Calidad para la Entidades Fiscalizadoras Superiores; el IIA Global, norma 1300 y 1310; el Colegio de Contadores Públicos de Costa Rica, el cual cuenta con un sistema de control de calidad; la Organización Internacional para la Estandarización (ISO, por sus siglas en inglés), la cual publicó las normas ISO 9000; la CGR que ha emitido normativa para asegurar la calidad de sus servicios, por ejemplo, las Directrices para la autoevaluación anual y la evaluación externa de calidad de las auditorías internas del Sector Público (D-2-2008-CO-DFOE), Normas para el ejercicio de la auditoría interna en el Sector Público (NEAI) (R-DC-119-2009) y las Normas Generales de Auditoría para el Sector Público (NGASP), entre otras.

\section{Unidades de Auditoría Interna (UAI)}

Las competencias de las UAI se rigen por la Ley General de Control Interno N. 8292 (Asamblea Legislativa de la República de Costa Rica, 2002) y la Ley Orgánica de la Contraloría General de la República N. 7428 (Asamblea Legislativa de la República de Costa Rica, 1994), se complementan con la normativa y las directrices emitidas por la CGR y demás órganos que regulen la profesión, las cuales son de acatamiento obligatorio. La UAI se ha transformado en los últimos años, debido a su papel de aliado estratégico en la organización, la cual genera valor agregado; sin embargo, es necesario fortalecer el trabajo de esta unidad staff y adoptar las mejores prácticas internacionales de los organismos especialistas en la materia, por ejemplo: preparación de planes de auditoría basados en riesgos, auditoría continua, modelo de las tres líneas de defensa y plan estratégico de la UAI.

Todas las organizaciones tienen sus fortalezas y debilidades en las diferentes áreas funcionales, por lo que el análisis FODA ayuda al desarrollo profesional del personal de las UAI. Estas unidades fiscalizadoras deben evaluarse y visualizar su situación, identificando fortalezas por mantener o reforzar $y$ debilidades por mejorar.

Ahora es oportuno hacer mención del marco conceptual. La investigación se desarrolla en el sector público de Costa Rica, mismo que está compuesto por instituciones que se encargan de las diferentes funciones del Estado y se clasifican según su naturaleza jurídica. Dado el aumento de las instituciones públicas $y$, por ende, un aumento en el gasto público y la corrupción, es de vital importancia que se mantenga un control sobre los fondos públicos y que dicha fiscalización sea realizada por un órgano contralor y las UAI. El aumento del gasto público en Costa Rica genera un aumento en la deuda pública, la cual se compone de las obligaciones que contraen, a nivel nacional e internacional, el Gobierno Central, el Banco Central de Costa Rica y el resto del Sector Público no financiero. Debido a lo anterior, queda evidenciado el grave problema de las finanzas públicas costarricenses y la importancia del papel que debe asumir la auditoría interna en el control de los ingresos y gastos públicos.

De lo anterior se desprende que el aseguramiento de la calidad de las unidades de auditoría interna debe ser considerado en las actividades de planificación, ejecución, comunicación y seguimiento, para la mejora continua, aplicando la normativa nacional e internacional.

Los resultados de la investigación muestran que, si bien las auditorías internas gubernamentales del sector público costarricense están conformadas por personal competente que reúne los requisitos académicos y experiencia para desempeñar el puesto, deben implementar una serie de recomendaciones para la mejora continua de sus labores de fiscalización, que permitan asegurar la calidad de sus productos. Las recomendaciones de cada una de las variables son las siguientes: 
- Metodología de las Unidades de Auditoría Interna para el aseguramiento de la calidad

1. Indicadores de gestión

2. Sistema de Aseguramiento de la Calidad

3. Autoevaluación anual de calidad

4. Auditoría operativa

5. Presupuesto

6. Principios de la gestión de la calidad de la norma INTE/ISO 9000:2015

7. Sistema de gestión de la calidad INTE/ISO 9001:2015

- Aplicación del marco normativo y mejoras prácticas

8. Mejores prácticas mundiales en auditoría interna

9. Herramientas tecnológicas

10. Aseguramiento de la calidad

11. Auditoría Interna reinventada

12. Análisis periódico de datos automatizados

- Fortalezas y debilidades de las Unidades de Auditoría Interna

13. Fuerte respeto $y$ credibilidad

14. Identificación de los riesgos de la institución

15. Independencia y objetividad

16. Recurso humano completo y calificado

17. Universo auditable

18. Sistema de gestión automatizado

19. Capacitación o formación profesional continua

\section{METODOLOGÍA}

En los siguientes apartados se describe la metodología de la investigación utilizada.

\section{Enfoque de investigación}

La investigación tiene un enfoque cuantitativo, en el cual se utilizaron instrumentos de carácter estadístico para abordar los datos de la investigación.

Tipo de investigación

De acuerdo con la temática que caracteriza al estudio que está relacionado con las UAI, el trabajo está orientado con un alcance de investigación descriptivo. El estudio abarca, la opinión y criterios de los profesionales que laboran en las UAI de las instituciones públicas.

\section{Población y muestra}

La población del trabajo de investigación está conformada por las UAI del sector gubernamental de los diferentes sectores, según clasificación establecida por la CGR (2018b). El total de UAI corresponde a 219, las cuales están conformadas por auditorías internas unipersonales hasta de 60 funcionarios. Para la selección de la muestra que se utiliza en el estudio, según Hernández Sampieri et al. (2014), es de tipo probabilística. Como resultado de aplicar la fórmula, se obtuvo una 
muestra probabilística de 17 UAI del sector público costarricense; sin embargo, al sumar las cinco unidades definidas a criterio del investigador, para ampliar los datos por las características que presenta la investigación, suma una muestra total de 22. Se utilizó el muestreo al azar del software de auditoría IDEA.

\section{Criterios de selección y técnicas e instrumentos}

Para obtener la información que sustentó el análisis de la investigación, el tipo de instrumento utilizado fue un cuestionario con escalonamiento tipo Likert, que de acuerdo con Hernández Sampieri et al. (2014), consiste en: "Conjunto de ítems que se presentan en forma de afirmaciones para medir la reacción del sujeto en tres, cinco o siete categorías” (p. 238).

De acuerdo con lo anterior, facilita la recolección de la información producto de la percepción de los sujetos participantes en el estudio que conducirá a la sistematización y validación de los datos. Para la aplicación de este tipo de cuestionario de escalamiento tipo Likert, se utilizaron las siguientes escalas de valoración o de frecuencias: Siempre, Algunas veces y Nunca. Además, el cuestionario tiene un total de 44 preguntas.

\section{Validación de instrumentos}

La validación del instrumento de investigación fue realizada por tres expertos auditores que no forman parte del objeto de estudio, los cuales revisaron el cuestionario para mejorarlo y completarlo, esta técnica de validación se conoce como juicio de experto. Finalmente, se aplicó una prueba piloto, para evaluar la calidad de las instrucciones y preguntas, así como el tiempo de respuesta.

Se realizó el análisis de confiabilidad, usando el paquete estadístico SPSS versión 21.0. En el caso del instrumento para el personal colaborador técnico de la UAI, el alfa de Cronbach es de 0,931, basado en los 44 ítems. Ninguno de ellos requiere ser eliminado para mejorar el valor del indicador. En el caso del instrumento para los auditores internos, el alfa de Cronbach es de 0,725, basado en los 44 ítems. En este caso, la eliminación de las frases no mejora el valor del indicador. Con esta información se concluye que hay consistencia en las escalas aplicadas a ambos grupos.

\section{Técnicas de recolección}

Para la recolección de datos, se utilizaron como fuentes primarias los auditores consultados de las UAI y la fuente secundaria fue el material que se obtuvo de la página web de las instituciones que están en la muestra. Una vez realizado el procedimiento de validez del instrumento, se elabora la versión final del mismo. Después, se obtienen los permisos para aplicar el instrumento y recolectar la información solicitada a cada uno de los auditores. Además, se han realizado consultas bibliográficas de investigaciones nacionales e internacionales, mediante la búsqueda virtual en Google académico, así como las bases de datos de la Universidad Estatal a Distancia, Universidad de Costa Rica y el Instituto Tecnológico de Costa Rica.

\section{Procesamiento de análisis}

El instrumento de recolección de datos fue aplicado a los auditores internos y personal colaborador técnico de la UAI. Una vez digitados los datos, se realizó un análisis descriptivo de cada una de las variables.

\section{RESULTADOS}


Las tres variables que sustentan la investigación son las siguientes:

1. Metodología de las UAI para el aseguramiento de la calidad.

2. Aplicación del marco normativo y mejoras prácticas.

3. Fortalezas y debilidades de las UAI.

\section{Caracterización de la población}

En primera instancia, se despliega la información correspondiente a las características del auditor interno de las UAI que participaron en la muestra del estudio. Con respecto al género de los auditores internos, la investigación arrojó que 10 corresponden a hombres y siete a mujeres, los cuales representan el 58,82 \% y 41,18 \%, respectivamente. Existe una cantidad mayor de profesionales varones que son los responsables de dirigir las diferentes UAI. Sobre la condición laboral de los auditores internos, un 94,12\%, es decir, 16 auditores internos consultados indican que se encuentran en propiedad y un auditor interno está como interino, es decir, un 5,88 \%. Esto por cuanto, por motivo de vacaciones, el auditor interno interino está sustituyendo al auditor interno titular. Respecto al nivel académico, nueve auditores internos tienen un título universitario de posgrado, representando un 52,94\% y ocho auditores internos tienen el grado de Licenciatura, es decir, un 47,06\%. Los profesionales consultados en el estudio evidencian un grado profesional académico transcendental para desarrollarse en su ámbito de competencia, razón por la cual se puede comprobar la idoneidad de su formación académica, preparación y capacitación, para ejercer las funciones de auditoría. En el cuadro 1 se despliega la información correspondiente a las características del auditor interno de las UAI que participaron en la muestra del estudio.

\begin{tabular}{|c|c|c|}
\hline & Absoluto & Porcentual \\
\hline \multicolumn{3}{|l|}{ Género } \\
\hline Mujer & 7 & 41.18 \\
\hline Hombre & 10 & 58.82 \\
\hline Total & 17 & 100,00 \\
\hline \multicolumn{3}{|l|}{ Condición laboral } \\
\hline Propiedad & 16 & 94.12 \\
\hline Interino & 1 & 5.88 \\
\hline Total & 17 & 100,00 \\
\hline \multicolumn{3}{|l|}{ Nivel Académico } \\
\hline Posgrado & 9 & 52.94 \\
\hline Licenciatura & 8 & 47.06 \\
\hline Bachiller & 0 & 0.00 \\
\hline Estudiante Universitario & 0 & 0.00 \\
\hline Total & 17 & 100,00 \\
\hline
\end{tabular}

Fuente: Elaboración propia con información proporcionada por los auditores internos del sector público costarricense, 2018. 
Debe señalarse que, con respecto a los años de experiencia en el puesto actual de auditor interno, más de la mitad de los consultados tiene más de 10 años de experiencia, que corresponden a 10 auditores internos, los cuales representan el 58,82 \%; cuatro auditores con un rango de 1 a 5 años, es decir, un 23,53\%; dos funcionarios de 6 a 10 años representan el 11,76\% del total y un auditor interno el 5,88\%. Relacionado con la experiencia, los Lineamientos sobre gestiones que involucran a la auditoría interna presentadas ante la CGR establecen en el acápite 2.1.1 lo siguiente:

El auditor deberá caracterizarse por su idoneidad para el puesto que desempeña. Por ello, será un profesional altamente capacitado en materia de auditoría y reunirá los conocimientos, la experiencia, las actitudes, y las habilidades para administrar la unidad de auditoría interna. (CGR, 2018a, p. 15)

El $100 \%$ de los auditores internos indicaron que la Unidad de Auditoría Interna de la institución para la cual trabajan tiene más de 10 años de constituida. La experiencia profesional del auditor es fundamental en las actividades del proceso de auditoría, por ese motivo, es un requisito para ejercer el cargo de auditor interno en una institución pública. La amplia experiencia del responsable de la UAI se espera que genere un mejor desempeño del departamento fiscalizador y, por ende, de la organización. El cuadro 2 detalla los datos de los años de experiencia del auditor interno.

CUADRO 2

AÑOS DE EXPERIENCIA EN EL PUESTO ACTUAL

\begin{tabular}{lcc}
\hline & Absoluto & Porcentual \\
\hline Menos de un año & 1 & 5.88 \\
De 1 a 5 años & 4 & 23.53 \\
De 6 a 10 años & 2 & 11.76 \\
Más de 10 años & 10 & 58.82 \\
Total & 17 & 100.00 \\
\hline
\end{tabular}

Fuente: Elaboración propia con información proporcionada por los auditores internos del sector público costarricense, 2018.

La investigación detalla la cantidad de funcionarios de las UAI y concluye que predominan las UAI de 2 a 10 funcionarios con un 41,18 \%, con un 29,41 \% las auditorías internas unipersonales y con el mismo porcentaje las UAI de más de 20 funcionarios.

En segunda instancia, se detallan las características del personal técnico colaborador de la auditoría interna que coadyuva al responsable de esta unidad. Para la característica del género, el $64,04 \%$ de los consultados corresponde a 57 hombres, mientras que un 35,96\% son 32 mujeres, para un total de 89 auditores. Tal como se observa, más del 50\% del personal colaborar técnico son hombres y menos del $40 \%$ son mujeres, lo cual refleja una desigualdad de género para este cargo de fiscalizador. El cuadro 3 muestra las características del personal de la auditoría interna que participaron en la muestra del estudio. 


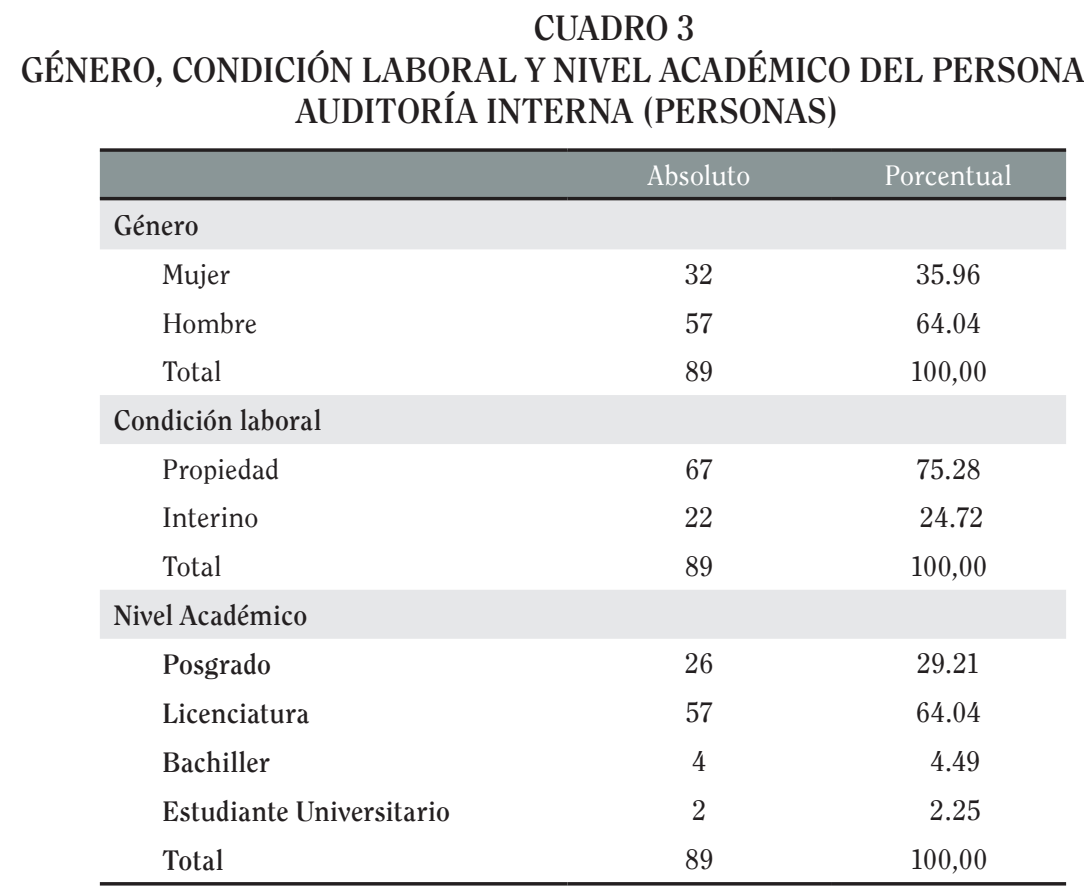

Fuente: Elaboración propia con información proporcionada por los auditores internos del sector público costarricense, 2018.

Ahora bien, sobre la condición laboral de los colabores técnicos de la UAI, los resultados comprueban que un $75,28 \%$ de los consultados han manifestado que se encuentran en propiedad, representado por 67 auditores y un $24,72 \%$ se encuentran en condición laboral de interino, es decir, 22 auditores. Las UAI forman parte de una serie de instituciones públicas que contienen un presupuesto ordinario destinado para los diferentes procesos administrativos, operativos o técnicos de la organización. Sin embargo, el presupuesto de las UAI varía según las características de la institución, como el servicio al usuario o la normativa aplicable. En virtud de lo anterior, el recurso humano, económico y tecnológico está destinado para una cantidad específica de funcionarios.

Resulta oportuno señalar que existen UAI que están limitadas en su presupuesto y en la cantidad de profesionales, lo cual les dificulta generar ascensos, reclasificación de puestos o nombramientos en propiedad. No obstante, los auditores internos sí pueden promover sanas prácticas en el manejo de personal, mediante un liderazgo positivo, como lo promueven las cuatro grandes firmas de consultoría y auditoría, llamadas Big Four y conformadas por KPMG, Deloitte, PWC y Ernst \& Young. El liderazgo positivo genera un mejor ambiente de trabajo para el personal, el cual incide en el rendimiento y gestión de la UAI.

Con la finalidad de determinar el nivel académico del personal técnico colaborador, se les consultó a los funcionarios de la UAI el grado académico o si están realizando estudios universitarios. En este sentido, se comprende que un $29,21 \%$ de los consultados tiene un posgrado, $64,04 \%$ es licenciado, 4,89 \% son bachilleres, es decir, un 98,14\%, que corresponde a 87 auditores, tienen un título universitario; mientras que un $2,25 \%$, es decir, dos colaboradores son estudiantes universitarios. Como lo prueban los resultados anteriores y conforme lo establece el acápite 105 Competencia y pericia profesional de las Normas Generales de Auditoría para el Sector Público (CGR, 2014), el personal de la auditoría interna debe tener las competencias propias para el ejercicio de sus funciones. Lo anterior refleja que las UAI del sector público costarricense están conformadas por personal muy preparado para ejercer su función fiscalizadora. 
Adicionalmente, la investigación refleja que 33 funcionarios de las UAI tienen más de 10 años de experiencia en el puesto actual, representando un 37,08 \%. De 6 a 10 años, hay 20 auditores, con un 22,47 \%, es decir, un 59,55\% de los fiscalizadores consultados tienen más de 5 años de experiencia. Mientras que 30 colaboradores de la UAI tienen de 1 a 5 años, lo cual significa un $33,71 \%$ y seis auditores tienen menos de un año de trabajar en el puesto actual, lo cual equivale a un $6,74 \%$. El anterior escenario evidencia que las UAI de la muestra cuentan con personal con experiencia para el puesto que desempeñan. Sobre el asunto de la antigüedad en años de la UAI de la institución, el estudio evidencia que 81 colaboradores trabajan en una UAI con más de 5 años de antigüedad, representando un $91,01 \%$ de los consultados, mientras que ocho funcionarios manifestaron que su UAI tiene de 1 a 5 años.

De acuerdo con los razonamientos que se han venido realizando, queda evidenciado en la investigación que las UAI consultadas corresponden a unidades fiscalizadoras con amplia experiencia, lo cual es un elemento importante que puede incidir en la calidad de la UAI. En resumen, de acuerdo con la percepción de los auditores internos y el personal técnico colaborador de las 22 UAI de la muestra seleccionada, se determinó que existe una cantidad mayor de profesionales varones que las dirigen.

De la misma manera, la mayoría del personal técnico colaborador son hombres. Con respecto a la condición laboral, prevalecen los funcionarios que están en propiedad. El nivel académico de los auditores internos y el personal técnico colaborador destaca, puesto que la mayoría son profesionales con un título universitario de posgrado y Licenciatura. De igual forma, destaca un rango de experiencia de más de 10 años para los auditores internos y el personal técnico colaborador, así como la antigüedad en años de la UAI. Finalmente, la mayoría de las UAI están compuestas por más de 20 funcionarios. En consecuencia, los resultados del cuestionario muestran que las UAI están conformadas por personal competente y en propiedad, con amplia experiencia en auditoría y laboran para auditorías internas con amplia trayectoria. El cuadro 4 despliega los datos de los años de experiencia en el puesto actual de los subalternos del auditor interno.

\section{CUADRO 4 \\ AÑOS DE EXPERIENCIA EN EL PUESTO ACTUAL DEL PERSONAL DE LA AUDITORÍA INTERNA}

\begin{tabular}{lcc} 
& Absoluto & Porcentual \\
\hline Menos de un año & 6 & 6.74 \\
De 1 a 5 años & 30 & 33.71 \\
De 6 a 10 años & 20 & 22.47 \\
Más de 10 años & 33 & 37.08 \\
Total & 89 & 100.00 \\
\hline
\end{tabular}

Fuente: Elaboración propia con información proporcionada por los auditores internos del sector público costarricense, 2018.

Sistematización y discusión de resultados

Para efectos del análisis de la información, se determinan los ítems 4, 18, 20 y 21 del cuestionario, con la finalidad de contrastar las opiniones de la población objeto de estudio de acuerdo con el sustento teórico y conceptual determinado en la investigación.

El Anexo $\mathrm{N}^{\circ} 1$ detalla la información brindada por los auditores internos de acuerdo con la primera variable del estudio, la cual se denomina Metodología de las Unidades de Auditoría Interna para el aseguramiento de la calidad, misma que comprende de la pregunta $\mathrm{N}^{\circ} 1$ a la $\mathrm{N}^{\circ} 21$. 
Sobre la percepción de los auditores internos para la pregunta 4, que consulta si existen indicadores de gestión que midan con cierta periodicidad la eficiencia y eficacia de la UAI, 10 auditores internos marcaron la opción "Siempre", lo que significa un 58,82\%; tres profesionales indican "Algunas veces", es decir, 17,65 \%; mientras que cuatro dicen que "Nunca", representando el 23,53 \%. Con respecto a la medición de la periodicidad, de la eficiencia y eficacia de la UAI, la norma 1300 de las Normas Internacionales para el Ejercicio Profesional de la Auditoría Interna del Instituto de Auditores Internos (2017) establece lo siguiente:

Un programa de aseguramiento y mejora de la calidad está concebido para permitir una evaluación del cumplimiento de las Normas por parte de la actividad de auditoría interna, y una evaluación de si los auditores internos aplican el Código de Ética. Este programa también evalúa la eficiencia y eficacia de la actividad de auditoría interna e identifica oportunidades de mejora. El director ejecutivo de auditoría debería alentar la supervisión del Consejo en el programa de aseguramiento y mejora de la calidad. (p.9)

La medición y análisis de los indicadores de gestión es una herramienta indispensable para las UAI, porque permite verificar si los objetivos estratégicos se están cumpliendo conforme a lo programado en el plan anual de trabajo de estas.

El ítem 18 consulta si, con el propósito de mejorar la gestión fiscalizadora e institucional, la UAI realiza anualmente una auditoría operativa para determinar los niveles de economía, eficacia, eficiencia y transparencia en el uso de dichos recursos. Seis auditores que representan el 35,29\% de los consultados marcaron la opción de "Siempre", cuatro como un 23,53 \% indican que "Algunas veces" y siete mencionan "Nunca", lo cual significa un 41,18 \%. La aplicación de la auditoría operativa en la gestión anual de la UAI evalúa a la organización desde otra perspectiva. Sandoval (2012) menciona que la auditoría operacional: "evalúa la eficiencia y eficacia de cualquier parte de los procedimientos y métodos de operación de una organización" (p.18). Según las NGASP de la CGR (2014), en la auditoría operativa se evalúa el uso de los recursos:

Evalúa la eficacia, eficiencia y economía con que la entidad, programa, proyecto, unidad, proceso o actividad del sujeto fiscalizado, utiliza los recursos públicos. Las organizaciones de auditoría deben seleccionar los temas de auditoría operativa por diferentes medios como la planificación estratégica y la identificación de riesgos y/o problemas. (p.3)

Por su parte, Paredes Soldevilla (2014) afirma que la auditoría operativa persigue, como parte de sus objetivos, determinar el grado de eficiencia, eficacia y economía con que se realizan las actividades básicas de la empresa. Cuando la UAI evalúa la productividad de los recursos humanos, materiales y financieros, puede identificar aspectos que eviten la duplicidad de funciones, incumplimiento de políticas, procedimientos, normas, así como el uso ineficiente del presupuesto asignado a los gastos. Como resultado de las consideraciones señaladas anteriormente, se hace necesario que las UAI incluyan en su plan anual de trabajo, auditorías operativas.

Por otra parte, el ítem 20 consulta si considera que se aplican los principios de la gestión de la calidad de la norma INTE/ISO 9001:2015 en su UAI. Según los datos obtenidos, cinco auditores internos mencionan que "Siempre", lo cual significa un 29,41\%; cuatro auditores indican "Algunas veces" un 23,53 \% y ocho profesionales dicen que "Nunca" con 47,06\%.

De acuerdo con Instituto de Normas Técnicas de Costa Rica (INTECO, 2015), la norma internacional ISO 9001:2015 se basa en los principios de la gestión de la calidad descritos en la Norma INTE / ISO 9000. Dichos principios comprenden los siguientes: enfoque al cliente, liderazgo, compromiso de las personas, enfoque a procesos, mejora, toma de decisiones basada en la evidencia y gestión de las relaciones; los cuales son relevantes en la gestión de la calidad, pero vale la pena 
resaltar el liderazgo y la mejora. El liderazgo es fundamental para el éxito de un grupo de trabajo $y$ en el caso particular de una UAI. Significa, entonces, que es muy importante que el auditor sea guiado por un líder que lo involucre y le explique los procedimientos internos de la UAI, así como la visión y misión de la entidad, para que exista un compromiso del equipo de auditoría en cumplir con el plan anual de trabajo y el plan estratégico. Con respecto a la mejora continua, es fundamental para que la organización mantenga los niveles de desempeño y generar nuevas oportunidades, así como beneficios clave potenciales, por ejemplo, mejora del desempeño del proceso, de las capacidades de la organización y de la satisfacción del cliente, del enfoque en la investigación y mejor uso del aprendizaje para la mejora. Similarmente, la pregunta 21 consulta si conoce los requisitos de calidad de los sistemas de gestión de la calidad de la norma INTE/ISO 9001:2015. Cinco auditores que representan el 29,41 \% de los consultados marcaron la opción de "Siempre", cuatro como un 23,53 \% indican que "Algunas veces" y ocho mencionan "Nunca", lo cual significa un 47,06\%.

Las respuestas de los consultados a las preguntas 20 y 21 coinciden en sus valores absolutos y relativos, debido a que ambas preguntas incorporan a la norma INTE/ISO 9001:2015. Resulta evidente un desconocimiento de la mayoría de los auditores internos en la norma INTE/ISO 9001:2015. De acuerdo con INTECO (2015), el aseguramiento de la calidad es: "parte de la gestión de la calidad (3.3.4) orientada a proporcionar confianza en que se cumplirán los requisitos de la calidad (3.6.5)" (p. 23). La adopción de un sistema de gestión de la calidad en una organización ayuda a mejorar su desempeño; sin embargo, implica una erogación importante que no todas las instituciones públicas están dispuestas a desembolsar por asuntos de presupuestos. No obstante, es claro que implementar un sistema de gestión de la calidad basado en la norma INTE/ISO 9001:2015 trae beneficios, como la organización de la documentación de los diferentes procesos de la entidad, mejora el rendimiento del proceso, se espera un aumento en los usuarios del producto, mejor control de los documentos, entre otros.

Al mismo tiempo, se obtuvo la percepción del personal técnico colaborador de la UAI para la primera variable: Metodología de las UAI para el aseguramiento de la calidad, que comprende de la pregunta 1 a la 21, cuyos resultados se muestran en el Anexo $\mathrm{N}^{\circ} 2$. Llama la atención que existe consistencia en las respuestas brindadas por los funcionarios que colaboran técnicamente con la UAI. En este caso particular, para efectos del análisis de la información, se determinan los ítems 7, 10 y 13, con la finalidad de contrastar las opiniones de la población objeto de estudio de acuerdo con el sustento teórico y conceptual determinado en la investigación.

La pregunta 7 consulta si considera que existe un sistema de aseguramiento de la calidad en la UAI. Según la percepción de los 89 auditores consultados, el 78,65 \% señala que "Siempre", mientras que el 19,10 \% indica "Algunas veces" y un 2,25 \% "Nunca". Los resultados de la consulta al personal técnico colaborador demuestran que tienen conocimiento de la existencia de un sistema de aseguramiento de la calidad en la UAI. Sucede pues que el aseguramiento de la calidad es abordado por diferentes autores nacionales e internacionales. De acuerdo con Castro López et al. (2015), la importancia de un buen sistema de aseguramiento de la calidad:

El aseguramiento de la calidad es de vital importancia en el proceso de auditoría, porque ayuda a las firmas auditoras, a garantizar de forma razonable frente a las entidades reguladoras, el cumplimiento de la normativa técnica y legal adoptada en el país.

Si las firmas de auditoría cuentan con un buen sistema de aseguramiento de la calidad pueden ayudar a que la rama de auditoría tenga un mayor crecimiento, demostrando ante terceros que sus trabajos están elaborados bajo estándares de calidad. (p. 4)

En torno a lo señalado en el párrafo anterior, el aseguramiento de la calidad es vital para fortalecer la forma de trabajar de las UAI y las auditorías externas, criterio que es ratificado en las NEAI de la CGR (2010), establecen en el acápite 1.3 que: "El auditor interno debe instaurar y velar 
por la aplicación de los procesos necesarios para el aseguramiento de la calidad en el ejercicio de la auditoría interna, mediante evaluaciones internas y externas" (p. 3).

Por su parte, la norma 210, Calidad en la auditoría, acápite 01 de la NGASP, igualmente emitidas por la CGR (2014), establece lo siguiente:

01. El aseguramiento de la calidad de la auditoría es una labor que debe ejecutarse durante cada una de las actividades del proceso de auditoría, con el propósito de asegurar que los insumos, las tareas realizadas y los productos generados cumplan oportunamente con los estándares profesionales y con los requerimientos establecidos en la normativa bajo un enfoque de efectividad y mejoramiento continuo. (p. 11)

El aseguramiento de la calidad es una labor que debe ejecutarse durante cada una de las actividades del proceso de auditoría relacionadas con la planificación, ejecución, comunicación y seguimiento de las recomendaciones emitidas por esta auditoría interna. Esta sana práctica mejora la gestión fiscalizadora de la UAI. La percepción del jerarca y la administración hacia la auditoría interna mejorará, lo cual aumentará la credibilidad ante terceros, por la buena gestión en el cumplimiento de sus funciones. La existencia de un sistema de aseguramiento de la calidad en la UAI impacta en la gestión diaria del departamento y la institución, generando procedimientos y herramientas de trabajo en cada una de las actividades del proceso de auditoría. Asimismo, permite mejorar en forma continua a la UAI, lo cual se traducirá en beneficios en el corto, mediano y largo plazo.

La pregunta 10 consulta si considera que se han aplicado cambios para mejorar la herramienta de autoevaluación anual de calidad de la CGR. Según la información obtenida de la percepción del personal técnico colaborador, 55 auditores internos señalan que "Siempre", para un 61,80\%; 21 auditores indican "Algunas veces" para un 23,60 \% y 13 profesionales mencionan "Nunca", es decir, 14,61 \% de los consultados. Por lo tanto, más de la mitad de los consultados expresaron que la herramienta de autoevaluación anual de la calidad de la CGR ha tenido mejoras. El numeral 1.4 de las directrices D-2-2008-CO-DFOE de la CGR (2008) establece que la: "autoevaluación anual de calidad es aquella mediante la cual la unidad de auditoría interna evalúa su calidad con respecto al período anual inmediato anterior" (p.2). Por su parte, el Instituto de Auditores Internos (2017) define en las Normas Internacionales para el ejercicio profesional de la auditoría interna, la norma 1311-Evaluaciones internas: "Las evaluaciones internas deben incluir: El seguimiento continuo del desempeño de la actividad de auditoría interna, y Autoevaluaciones periódicas o evaluaciones por parte de otras personas dentro de la organización con conocimientos suficientes de las prácticas de auditoría interna” (p. 9).

Sobre el tema de los cambios para la mejora de la herramienta, es necesario indicar que el instrumento facilitado por la CGR podría ser sujeto a mejoras, considerando que la misma no cuenta con cierta información para determinar los riesgos por parte de la UAI y el uso de papeles de trabajo de apoyo para aplicar en diferentes pruebas o revisiones. Adicionalmente, la autoevaluación anual de calidad de la UAI no hace referencia a las normas de calidad ISO y las mejores prácticas internacionales, de manera tal que promueva su aplicación en la gestión de la UAI. En virtud de lo anterior, si bien la mayoría del personal técnico colaborador consultado considera que se han aplicado cambios para mejorar la herramienta de autoevaluación anual de calidad de la CGR, aplicando el principio de calidad de mejora continua, es recomendable fortalecer la herramienta mediante la actualización periódica de la misma, con la inclusión de temas de riesgo, papeles de trabajo, normas ISO y mejores prácticas internacionales.

La pregunta 13 consulta al personal de la UAI sobre si las autoevaluaciones o evaluaciones externas de calidad de la UAI han generado mejoras importantes en la gestión de la auditoría interna. Se concluye que el 62,92 \% de los auditores consultados declaró "Siempre", mientras que un 30,34 \% y 6,74 \%, mencionaron "Algunas veces" y "Nunca", respectivamente. La autoevaluación 
o evaluaciones externas de calidad de la UAI verifican si se aplican las normas de auditoría aplicables, con el propósito de mejorar la gestión de la auditoría interna y añadir valor a la organización para la cual trabajan. La CGR (2008) menciona que la revisión externa de calidad: "Es aquella efectuada por un sujeto calificado, independiente y externo a la institución para examinar la calidad de la auditoría interna" (p.3). Se considera que las autoevaluaciones o evaluaciones externas de la calidad, realizadas a las UAI del sector público costarricense, son fundamentales para la gestión diaria de las mismas. Por lo tanto, es de esperar que el evaluador genere recomendaciones que impacten a la UAI.

La segunda variable que abarca la aplicación del marco normativo y mejores prácticas muestra los porcentajes absolutos y relativos del ítem 22 al 37. En este caso particular, para efectos del análisis de la información, se determinan los ítems 32, 33 y 35 del cuestionario aplicado. El Anexo $\mathrm{N}^{\circ} 3$ incorpora los resultados de ítem 22 al 37.

La pregunta 32 consulta si la UAI aplica las mejores prácticas mundiales en la metodología para el aseguramiento de la calidad, como parte del proceso de mejora continua. Según el cuestionario aplicado, el 35,29 \% de los auditores internos señalan que "Siempre", 52,94 \% "Algunas veces" y 11,76 \% "Nunca". Las UAI deben reinventarse y aplicar mejores prácticas en su gestión diaria, que implique la generación de nuevas metodologías de trabajo, aplicando la normativa vigente, pero con la iniciativa de ir más allá de la revisión del control interno de la institución. De acuerdo con las Normas Generales de Auditoría en el Sector Público de la CGR (2014), las mejores prácticas son:

Prácticas administrativas de reconocida aceptación general y que devienen en un beneficio real para el ente u órgano, en virtud de que fortalecen el sistema de control interno, favorecen que la Administración realice una gestión adecuada y por lo tanto, contribuyen en el logro de los objetivos institucionales y apoyan la toma de decisiones. (p. 19)

Un ejemplo de sanas prácticas en auditoría interna es la auditoría continua. De acuerdo con Pugliese (2017), auditoría continua: "Es un método utilizado para llevar a cabo evaluaciones de control y riesgo de forma automática en una base más frecuente" (p.3). Asimismo, la preparación de planes de auditoría basados en riesgos se considera una buena práctica para las UAI. Según las Normas Internacionales para el Ejercicio Profesional de la Auditoría Interna, del Instituto de Auditores Internos (2017), la norma 2010-Planificación establece lo siguiente: "El director ejecutivo de auditoría debe establecer un plan basado en los riesgos, a fin de determinar las prioridades de la actividad de auditoría interna. Dichos planes deberán ser consistentes con las metas de la organización" (p. 12).

Los resultados de la consulta del ítem 32 muestran que las UAI no aplican las mejores prácticas mundiales en la metodología para el aseguramiento de la calidad. Las mejores prácticas enumeradas contribuyen a la gestión diaria de las actividades del proceso de auditoría interna. Además, promueven la mejora continua de la UAI y el entorno de control de la organización. Con la implementación de sanas prácticas como la auditoría continua, la planificación basada en riesgo, así como la planificación estratégica, entre otras, la UAI fortalecerá su departamento para la generación de informes más robustos y con recomendaciones con valor agregado para la institución.

El ítem 33 consulta si se utilizan en la UAI herramientas tecnológicas para sus evaluaciones. Del total de los 17 consultados, nueve auditores internos manifiestan que "Siempre", lo cual corresponde a un 52,94\%; un auditor interno representa el 5,88 \% y menciona que "Algunas veces", mientras que siete profesionales, un 41,18 \%, declararon que "Nunca". Resulta claro que la implementación de herramientas tecnológicas en la UAI promueve beneficios para este departamento fiscalizador y que, paralelamente, mejoran la gestión de la entidad, producto de las recomendaciones que se generan de los informes de la auditoría interna. El uso de herramientas 
tecnológicas en la UAI es una buena práctica para el control de las actividades del proceso de auditoría y para la calidad de la gestión, contribuyendo de esta manera al logro de los objetivos de esta. La auditoría continua es un buen ejemplo para resaltar la importancia del uso de la tecnología en el quehacer diario de la UAI. De acuerdo con la Guía para implantar con éxito un modelo de Auditoría Continua (2014), del Instituto de Auditores Internos de España (2017), indica que la auditoría continua: "permite evaluar los riesgos y sus controles, y realizar auditorías internas de carácter sustantivo, de manera automática y frecuente" (p. 7). Por su parte, Pedwar Castillo (2015) en su exposición Auditoría Continua Tendencia Global de la Auditoría Interna, manifiesta lo siguiente:

- La Auditoría Continua es un método empleado para realizar evaluaciones de riesgos y de controles de manera automática y más frecuente

- AC debe ir más allá de las fronteras de AI

- Debe lograr la integración de personas, procesos y la tecnología

- Mayor eficiencia de la auditoría al cubrir al 100\% de las transacciones electrónicas y permitir la detección temprana del fraude

- AC muchas veces genera auditorías especiales, concentrando los esfuerzos de auditorías en áreas de alta riesgo. (p. 65)

La cantidad y calidad de información que se logra obtener mediante el uso de herramientas tecnológicas corresponde a una de las ventajas que tiene la UAI. Con el uso frecuente de estas herramientas, se pueden detectar y prevenir fraudes, así como el ahorro de tiempo y personal en pruebas de campo que eventualmente se realizaban de forma manual. Siendo las cosas así, resulta claro que la implementación de herramientas tecnológicas en la UAI promueve beneficios para este departamento fiscalizador y que, paralelamente, mejoran la gestión de la entidad, producto de las recomendaciones que se generan de los informes de la auditoría interna.

La pregunta 35 consulta si la metodología de trabajo de la UAI, para el aseguramiento de la calidad, ha permitido el incremento de la productividad del personal de su departamento. Se observó que, de los 17 consultados, un 52,94 \% indicó "Siempre", 29,41 \% "Algunas veces" y 17,65 $\%$ "Nunca". El aseguramiento de la calidad es un proceso continuo que requiere de un esfuerzo en conjunto de los funcionarios de las UAI. El tener una calidad de excelencia no es tarea fácil; sin embargo, se puede asegurar la calidad de la Unidad aplicando las normas de auditoría que establecen la práctica obligatoria de evaluaciones internas de calidad en forma periódica y continua, así como evaluaciones externas.

El aseguramiento de la calidad es un proceso continuo que requiere de un esfuerzo en conjunto de los funcionarios de las UAI. El tener una calidad de excelencia no es tarea fácil; sin embargo, se puede lograr aplicando las normas de auditoría que establecen la práctica obligatoria de evaluaciones internas de calidad en forma periódica y continua, así como evaluaciones externas. El concepto de calidad data de mejores prácticas internacionales emitidas por organismos como la Organización Internacional para la Estandarización. Estas buenas prácticas han sido adoptadas por la INTOSAI y la IFAC, que son las fuentes normativas de referencia de las NGASP de la CGR (2014). En este sentido, se comprende que las UAI cuentan con normativa nacional e internacional como referencia para la implementación de sanas prácticas para la mejora continua, como la auditoría continua.

Seguidamente, se presentan los resultados de la percepción del personal técnico colaborador de la segunda variable, relacionada con el marco normativo y mejores prácticas, que comprende del ítem número 22 al 37. En este caso particular, para efectos del análisis de la información, se explican los resultados de los ítems 35, 36 y 37. El Anexo N4 incorpora los resultados de ítem 22 al 37.

El ítem 35 consulta si la metodología de trabajo de la UAI, para el aseguramiento de la calidad, ha permitido el incremento de la productividad del personal de su departamento. El 
personal técnico colaborador de la UAI manifestó un 71,91 \% para la opción "Siempre", 23,60 \% "Algunas veces" y un 4,49 \% "Nunca". La UAI debe realizar su labor de una manera eficiente y efectiva, para ello es necesario considerar el aseguramiento de la calidad, como un elemento de apoyo indispensable y permanente en las actividades de planificación, ejecución, comunicación y seguimiento.

El aseguramiento de la calidad ha sido mencionado por la Federación Latinoamericana de Auditores Internos (FLAI) en el Congreso Latinoamericano de Auditores Internos (CLAI), realizado en Chile 2015, Argentina 2017 y Brasil 2018, y organizado por el Instituto de Auditores Internos de los países mencionados (Instituto de Auditores Internos de Argentina y Federación Latinoamericana de Auditores Internos, 2017; Instituto de Auditores Internos de Brasil y Federación Latinoamericana de Auditores Internos, 2018; Instituto de Auditores Internos de Chile A.G. y Federación Latinoamericana de Auditores Internos, 2015; Instituto de Auditores Internos de Costa Rica, 2014).

Para tal efecto, la UAI ha cambiado su forma de trabajar, enfocada en el control de los riesgos $y$ haciendo uso de sanas prácticas mundiales, como la auditoría continua.

Por su parte, la pregunta 36 consulta si las mejores prácticas mundiales aplicadas en la metodología de trabajo para el aseguramiento de la calidad de la UAI han permitido la mejora del entorno de control de la organización. Los resultados obtenidos en el personal de la UAI muestran que el 62,92 \% seleccionó "Siempre", 31,46 \% "Algunas veces" y un 5,62 \% "Nunca”. Conforme se explicó en líneas anteriores, la implementación de la auditoría continua en la UAI aporta múltiples beneficios, entre los que destacan, la reducción de costos, incremento de la productividad y el mejoramiento de la organización. Sin embargo, los auditores internos y personal de la UAI no están $100 \%$ convencidos del incremento de la productividad del personal, producto del aseguramiento de la calidad. Según el Instituto de Auditores Internos (2015), la auditoría continua:

(...) es la combinación de las evaluaciones continuas de riesgos y controles apoyada a través de la tecnología. La auditoría continua está diseñada para que el auditor interno pueda reportar sobre un determinado tema en un plazo mucho menor que bajo el enfoque tradicional. (p. 6)

El ítem 37 consulta si realiza la UAI análisis periódico de datos automatizados que permitan realizar evaluaciones de riesgos y controles para determinar oportunidades de mejora en la gestión diaria de la institución. Para el caso del personal técnico colaborador de la UAI, estos manifestaron para la opción "Siempre" un 70,79 \%, 25,84 \% para "Algunas veces" y un 3,37 \% para "Nunca". Al igual que los anteriores autores, Martínez Fallas (2015) resalta la importancia de la auditoría continua en el análisis de la información de la entidad:

(...) supervisión constante de los controles mediante herramientas tecnológicas para prevenir la materialización de riesgos e impactos negativos en la empresa. El propietario y responsable de esta iniciativa es el departamento de auditoría, el cual tiene como norte el desarrollo de un proceso que busque la inmediatez en la prevención y alerta de posibles situaciones riesgosas, buscando llegar prácticamente a una auditoría concomitante. (p. 6)

En síntesis, con el análisis periódico de datos automatizados con el uso de herramientas como la auditoría continua, la UAI tiene mayor capacidad para identificar riesgos y mitigarlos, lo cual se traduce en valor agregado para la institución.

La tercera variable que abarca las fortalezas y debilidades de las UAI muestra los siguientes resultados de la aplicación del instrumento de consulta a los auditores internos y personal técnico 
colaborador de la UAI. A continuación, se detallan los porcentajes absolutos y relativos del ítem 38 al 44 de la percepción del auditor interno. El Anexo $\mathrm{N}^{\circ} 5$ incorpora los resultados de ítem 38 al 44 .

La pregunta 38 consulta si ha notado que existe un fuerte respeto y credibilidad hacia los funcionarios de la UAI, por parte del jerarca y titulares subordinados. De los 17 profesionales consultados, se determinó que el 64,71 \% indica "Siempre", 23,53 \% "Algunas veces" y el 11,76 \% "Nunca". Es importante resaltar estos datos, debido a que las 22 instituciones de la muestra sobrepasan los 15 años de constituidas.

Según Sandoval Morales (2012), el profesional de auditoría debe crearse una imagen de respeto: "El auditor deberá en todo momento dignificar la profesión ofreciendo una calidad profesional y personal, creando una imagen positiva y de respeto por parte de la organización” (p. 42). Por su parte, Chavarría Barrantes et al. (1997) destacan el concepto de credibilidad: "La importancia de la auditoría externa radica en que el dictamen de un auditor independiente le brinda credibilidad a la información financiera de la empresa" (p. 121). El auditor interno debe convencer a la administración de que está liderando un grupo de trabajo que está realizando trabajos con valor agregado. Para ello, el líder de la UAI debe guiar a cada uno de los funcionarios a ser personas responsables, con valores éticos y morales, que trabajen con respeto y consideración hacia el auditado.

El ítem 39 consulta si considera que, para la elaboración del plan estratégico y plan anual de trabajo de la UAI, se efectuó una adecuada identificación de los riesgos de la institución. Se pudo cuantificar que el $64,71 \%$ de los auditores internos señaló "Siempre", 29,41\% "Algunas veces" y 5,88\% "Nunca". De acuerdo con las Normas Internacionales para el Ejercicio Profesional de la Auditoría Interna, del Instituto de Auditores Internos (2017), la norma 2010-Planificación establece lo siguiente: "El director ejecutivo de auditoría debe establecer un plan basado en los riesgos, a fin de determinar las prioridades de la actividad de auditoría interna. Dichos planes deberán ser consistentes con las metas de la organización" (p. 12). Según Bustamante Sánchez (2014), es conveniente diseñar un plan de auditoría de gestión basada en riesgos para mejorar los procesos de una organización. La identificación de los riesgos de la institución permite a las UAI tomar decisiones y anticiparse a la administración en la detección oportuna de recomendaciones que permitan prevenir desastres y amenazas hacia la entidad. Por ejemplo, inundaciones, riesgos tecnológicos, operativos, legales, financieros, etc.

La pregunta 41 consulta si considera que la UAI cuenta con recurso humano completo y calificado para llevar a cabo sus funciones. En cuanto a las respuestas de los consultados, un 41,18 $\%$ de los auditores internos expresaron "Siempre", es decir, menos de la mitad; 41,18\% "Algunas veces" y 17,65\% "Nunca". En lo que respecta al recurso humano, la Norma Internacional de Control de Calidad 1 de la INTOSAI (2008) establece en la ISSAI 40 Control de Calidad para la EFS, que uno los elementos de un sistema de control de calidad son los recursos humanos. Por su parte, la Ley General de Control Interno (Asamblea Legislativa de la República de Costa Rica, 2002) menciona en el artículo 27 que el jerarca de los entes y órganos sujetos a esta Ley deberá asignar los recursos humanos, materiales, tecnológicos, de transporte y otros necesarios y suficientes para que la auditoría interna pueda cumplir su gestión.

Por otra parte, el ítem 42 consulta si considera que la UAI cuenta con los recursos humanos, materiales, tecnológicos, de transporte y otros, necesarios para cubrir el universo auditable en un periodo razonable. El 29,41 \% de los auditores internos consultados respondió que "Siempre", 35,29 \% "Algunas veces" y 35,29 \% "Nunca". Los procesos o áreas por auditar, conocidos como universo auditable, deben quedar definidos en el plan estratégico y operativo de la UAI, así como los recursos humanos, materiales, tecnológicos, de transporte y otros que son necesarios para cubrir ese universo auditable en un periodo razonable.

La pregunta 43 consulta si posee la UAI un sistema de gestión automatizado que permita registrar las actividades del proceso de auditoría, relacionadas con la planificación, ejecución, comunicación y seguimiento de recomendaciones. El 41,18 \% de los auditores internos consultados 
indica "Siempre", 17,65 \% "Algunas veces" y 41,18 \% "Nunca". Como debilidades de las prácticas procedimentales de las UAI, se puede mencionar la falta de un sistema de gestión de las diferentes actividades de la auditoría interna.

El ítem 44 consulta si existe en la UAI un programa de educación y capacitación profesional continua que permita mejorar la gestión diaria y calidad del departamento. De los auditores internos consultados, el 52,94 \% tiende a decir que "Siempre" y 23,53 \% para la opción de "Algunas veces" y "Nunca". El tema de la capacitación es abordado por la CGR (2014) en las NGASP en el acápite 107 Educación profesional continua, que establece lo siguiente: "El personal de auditoría debe mantener $y$ perfeccionar sus capacidades y competencias profesionales mediante la participación en programas de educación y capacitación profesional continua” (p. 5). La preparación del personal es importante para los responsables de dirigir las UAI, pues se comprobó que más del $50 \%$ de los auditores internos opina que existe un programa de educación continua en su UAI, tema relevante en la profesión que permite mejorar la gestión fiscalizadora.

La percepción del personal de la auditoría interna de la variable Fortalezas y debilidades de las UAI, que incluye del ítem 38 al 44, se detalla en el Anexo $\mathrm{N}^{\circ} 6$. Los porcentajes absolutos y relativos del ítem 38, 39, 40, 41 y 42, de la variable de análisis: Fortalezas y debilidades de las UAI, según percepción del personal técnico colaborador, son los siguientes:

El ítem 38 consulta si ha notado que existe un fuerte respeto y credibilidad hacia los funcionarios de la UAI, por parte del jerarca y titulares subordinados. La opinión del personal técnico colaborador de la UAI para la opción de "Siempre" indica un 65,17 \%, la cual es muy consistente con la indicada por los auditores internos; sin embargo, cambia la opinión para los aspectos de "Algunas veces" y "Nunca", con un 34,83 \% y 0,00 \%, respectivamente. Todas las organizaciones tienen sus fortalezas y debilidades en las diferentes áreas funcionales. El análisis FODA ayuda al desarrollo profesional del personal de las UAI. Estas unidades fiscalizadoras deben evaluarse y visualizar su situación, identificando fortalezas por mantener o reforzar y debilidades por mejorar.

La pregunta 39 consulta si considera que, para la elaboración del plan estratégico y plan anual de trabajo de la UAI, se efectuó una adecuada identificación de los riesgos de la institución. El personal técnico colaborador de la UAI manifestó para la opción "Siempre" 80,90 \%, 19,10 \% "Algunas veces" y 0,00\% para "Nunca". Las respuestas del personal técnico colaborador confirman la importancia de la adecuada identificación de los riesgos de la institución para elaborar el plan estratégico y plan anual de trabajo de la UAI.

El ítem 40 consulta si el personal de la UAI ejerce sus funciones con independencia y objetividad. Del total de los consultados del personal técnico colaborador de la UAI, casi la totalidad indican "Siempre" con un 94,38 \% y para las opciones "Algunas veces" y "Nunca", fueron un 5,62 \% y $0,00 \%$. En relación con lo anterior, la Ley General de Control Interno establece lo siguiente: "Artículo 25. Independencia funcional y de criterio. Los funcionarios de la auditoría interna ejercerán sus atribuciones con total independencia funcional y de criterio respecto del jerarca y de los demás órganos de la administración activa" (Asamblea Legislativa de la República de Costa Rica, 2002, art. 25).

Según Mendívil Escalante (2010), la definición de independencia de criterio es la siguiente: "Es la capacidad para expresar juicios y opiniones de manera imparcial, sin alterarlos en sentido alguno por presiones económicas, familiares, sociales o de cualquier naturaleza" (p. 5). La UAI está conformada por personal con un grado de independencia suficiente para poder realizar el trabajo objetivamente $y$, después, mediante un informe, se comunican los resultados obtenidos, del cual se espera que genere valor agregado para la organización.

La pregunta 41 consulta si considera que la UAI cuenta con recurso humano completo y calificado para llevar a cabo sus funciones. El personal técnico colaborador de la UAI manifestó un 70,79 \% "Siempre", 29,21 \% "Algunas veces" y 0,00 \% "Nunca". Con respecto a los recursos 
humanos de la auditoría, en el acápite 6.3.3 de los Lineamientos sobre gestiones que involucran a la auditoría interna presentadas ante la Contraloría General de la República, la CGR (2018a) establece lo siguiente: "La Auditoría Interna debe contar con un número determinado de funcionarios que les permita ejercer su actividad con la debida oportunidad, cobertura y disponibilidad" (p. 40). El contratar capital humano idóneo y comprometido es una ventaja para la UAI, la cual genera productos y servicios de calidad, aunado al mejoramiento continuo, con la finalidad de garantizar el éxito de la unidad fiscalizadora y la organización.

Por último, el ítem 42 consulta si considera que la UAI cuenta con los recursos humanos, materiales, tecnológicos, de transporte y otros, necesarios para cubrir el universo auditable en un periodo razonable. El personal técnico colaborador de la UAI señaló para la opción de "Siempre" $66,29 \%$, "Algunas veces" 32,58 \% y para "Nunca" 1,12 \%. Instituto de Auditores Internos (2017), en la norma 2030 Administración de recursos de las Normas internacionales para el ejercicio profesional de la auditoría interna, señala lo siguiente: "El director ejecutivo de auditoría debe asegurar que los recursos de auditoría interna sean apropiados, suficientes y eficazmente asignados para cumplir con el plan aprobado" (p. 13). Los recursos asignados para la adecuada gestión del plan anual de trabajo de la UAI deben ser utilizados eficientemente, en procura de brindar un servicio de calidad al auditado.

\section{CONCLUSIONES}

Con base en la percepción de los auditores internos y el personal técnico colaborador de las 22 UAI del sector público costarricense de la muestra seleccionada, se determinó que existe una cantidad mayor de profesionales varones que tienen a su cargo la responsabilidad de la UAI. De igual forma, la mayor parte del personal técnico colaborador son hombres. En relación con la condición laboral, prevalecen los funcionarios que se encuentran en propiedad y la minoría en condición de interino. Además, los auditores internos consultados cumplen con el nivel académico requerido por la CGR para ejercer el cargo. La mayoría de los auditores internos y el personal técnico colaborador son profesionales con un título universitario de posgrado y Licenciatura, con experiencia y laboran para UAI con amplia trayectoria. Las conclusiones se presentan con base en las variables que sustentaron el estudio, las cuales se exponen a continuación:

\section{Metodología de las Unidades de Auditoría Interna para el aseguramiento de la calidad}

\section{Indicadores de gestión}

El estudio evidencia, de acuerdo con la variable en mención, que los auditores internos y el personal técnico colaborador manifestaron que no incorporan regularmente en sus prácticas profesionales la medición periódica de la eficiencia y eficacia de la UAI, mediante los indicadores de gestión. La medición y análisis de los indicadores de gestión es una herramienta indispensable para las UAI, porque permite verificar si los objetivos estratégicos se están cumpliendo conforme a lo programado en el plan anual de trabajo de la UAI.

Sistema de aseguramiento de la calidad

Los auditores internos y el personal técnico colaborador consideran que existe un sistema de aseguramiento de la calidad en la UAI, el cual impacta en la gestión diaria del departamento 
fiscalizador y la institución, además, genera procedimientos y herramientas de trabajo en cada una de las actividades del proceso de auditoría.

Autoevaluación anual de calidad

La investigación precisa que se incluyen las Directrices para la autoevaluación anual de calidad de las auditorías internas del Sector Público, en procura del adecuado direccionamiento de las UAI. Asimismo, se evidencia que se cumple con las directrices de la CGR, con la aplicación de la autoevaluación de la calidad, la cual es una ayuda idónea para que las UAI identifiquen aspectos por mejorar y establezcan planes de corto, mediano y largo plazo para subsanar las debilidades encontradas.

\section{Auditoría operativa}

El estudio destaca que la auditoría operativa fiscaliza que la administración utiliza los recursos públicos de los diferentes procesos de manera eficiente, eficaz, económica y transparente, lo cual evidencia la importancia de este tipo de evaluaciones por parte de las UAI y que tiene injerencia en la toma de decisiones del jerarca, titulares subordinados, los objetivos y metas de la organización. Sin embargo, la población objeto de estudio considera que las UAI no incluyen en forma regular en el plan anual de trabajo este tipo de revisiones.

\section{Presupuesto}

Más de la mitad de los auditores internos consultados opinan que el presupuesto asignado a la UAI no siempre es suficiente para una adecuada gestión de la calidad. Caso contrario, más de la mitad del personal técnico colaborador consultado opina que la UAI tiene los recursos necesarios para ejecutar el plan anual de trabajo.

\section{Principios de la gestión de la calidad de la norma INTE/ISO 9000:2015}

El estudio revela que los principios de la gestión de la calidad son fundamentales en la gestión diaria de las UAI del sector público costarricense; sin embargo, el 47,06 \% de los consultados indicaron que nunca se han aplicado dichos principios y un 23,53 \% indica que algunas veces. La implementación de estos principios puede garantizar buenos resultados, incluida la motivación para todo el personal de las UAI. La norma internacional ISO 9001:2015 se basa en los principios de la gestión de la calidad descritos en la Norma INTE / ISO 9000.

\section{Sistema de gestión de la calidad INTE/ISO 9001:2015}

Un sistema de gestión de la calidad en la UAI genera valor, porque promueve la capacitación continua de los auditores, incrementa la motivación del grupo para el cumplimiento de las metas, mejora la imagen del departamento, promueve la innovación y el aprendizaje organizacional. La aplicación de las normas ISO 9001 en una organización es una decisión estratégica que permite la mejora continua, lo cual genera beneficios a corto, mediano y largo plazo. A pesar de todos los beneficios que genera un sistema de gestión de la calidad, el nivel de respuesta del personal 
técnico colaborador fue un 41,57 \% para la opción siempre, nuevamente surge la interrogante del desconocimiento de la norma por parte de los auditores.

\section{Aplicación del marco normativo y mejores prácticas}

Mejores prácticas mundiales en auditoría interna

Las respuestas brindadas por los auditores internos y el personal técnico colaborador de la UAI evidencian que las auditorías internas no aplican al $100 \%$ las mejores prácticas mundiales en la metodología para el aseguramiento de la calidad, lo cual afecta el proceso de mejora continua del departamento.

\section{Herramientas tecnológicas}

Se puede determinar en la consulta realizada a los profesionales que participaron en el estudio, que se implementa el uso de herramientas tecnológicas en la UAI, como buena práctica para el control de las actividades del proceso de auditoría y para la calidad de la gestión, contribuyendo de esta manera al logro de los objetivos de la UAI.

\section{Aseguramiento de la calidad}

El estudio destaca que el aseguramiento de la calidad es un proceso continuo que requiere de un esfuerzo en conjunto de los funcionarios de las UAI. El tener una calidad de excelencia no es tarea fácil; sin embargo, se puede asegurar la calidad de la UAI aplicando las normas de auditoría, que establecen la práctica obligatoria de evaluaciones internas de calidad en forma periódica y continua, así como evaluaciones externas.

\section{Auditoría Interna reinventada}

El estudio demuestra que la UAI debe incorporar en su metodología de trabajo para el aseguramiento de la calidad, las mejores prácticas mundiales, como la auditoría continua, la planificación estratégica, el modelo de las tres líneas de defensa, entre otros. El modelo de las tres líneas de defensa beneficia a la organización en la creación de una cultura que permita a cada proceso asumir la responsabilidad por gestionar riesgos y generar controles, dentro de los que se puede citar a la UAI como tercera línea de defensa y como cuarta línea de defensa a la auditoría externa.

Análisis periódico de datos automatizados

La investigación destaca que las herramientas tecnológicas facilitan el análisis periódico de los datos y permite generar información oportuna para el análisis y la toma de decisiones. Asimismo, genera beneficios como el ahorro y detección de oportunidades de mejora, previene a la administración de posibles fraudes y riesgos.

\section{Fortalezas y debilidades de las Unidades de Auditoría Interna}

Fuerte respeto $y$ credibilidad

El estudio demuestra que más del $50 \%$ de los auditores internos y personal técnico colaborador opinan que existe un fuerte respeto y credibilidad hacia los funcionarios de la UAI. 
El auditor interno debe convencer a la administración de que está liderando un grupo de trabajo que realiza auditorías con valor agregado. Para ello el líder de la UAI debe guiar a cada uno de los funcionarios a ser personas responsables, con valores éticos y morales, que trabajen con respeto y consideración hacia el auditado.

\section{Identificación de los riesgos de la institución}

La identificación de los riesgos en la planificación de la UAI es fundamental para el desarrollo de las actividades del proceso de auditoría. En este sentido, las respuestas de los consultados están orientadas a una planificación estratégica y operativa de la UAI, basada en los riesgos de la institución, enfocándose en las áreas o procesos significativos, según el tipo de riesgo que enfrenta.

\section{Independencia y objetividad}

El estudio concluye que el personal de la UAI debe ser independiente de la administración para evaluar objetivamente sus acciones; sin embargo, depende del jerarca para efectos administrativos, como permisos, incapacidades, vacaciones, presupuestos, autorizaciones, etc. Los auditores internos son independientes cuando emiten informes con juicios imparciales y neutrales. Las opiniones de todos los auditores internos y la mayoría del personal técnico colaborador consultados coinciden en que el personal de la UAI ejerce sus funciones con independencia y objetividad.

\section{Recurso humano completo y calificado}

Se evidenció conforme al análisis realizado que, si bien la normativa nacional e internacional resaltan la importancia del recurso humano para la gestión y calidad de la UAI, menos de la mitad de los auditores internos consultados considera que la UAI siempre cuenta con recurso humano completo y calificado para realizar sus labores. La mayoría del personal técnico colaborador considera que la UAI cuenta con recurso humano completo y calificado para llevar a cabo sus funciones.

\section{Universo auditable}

Según la opinión de los auditores internos y el personal técnico colaborador, los procesos o áreas por auditar, conocidos como universo auditable, deben quedar definidos en el plan estratégico y operativo de la UAI, así como los recursos humanos, materiales, tecnológicos, de transporte y otros que son necesarios para cubrir ese universo auditable en un periodo razonable.

\section{Sistema de gestión automatizado}

La investigación apunta que la falta de un sistema de gestión de las diferentes actividades del proceso de auditoría es una debilidad de las UAI, lo cual fue confirmado por los auditores internos consultados. Sin embargo, la respuesta del personal técnico colaborador es muy positiva, casi el 90 \% respondió que la UAI tiene un sistema de información para las diferentes actividades del proceso de auditoría.

\section{Capacitación profesional continua}


El estudio indica que es vital y trascendental la capacitación profesional continua a corto, mediano y largo plazo, con la intención de tener un personal calificado y productivo que se especialice en áreas que normalmente no revisa. Por ejemplo, auditoría de sistemas de información, auditorías de proyectos de inversión, contratación administrativa, auditorías operativas, entre otros. Un personal capacitado garantiza un profesional con habilidades para desempeñar mejor sus labores. Además, es importante indicar que más del $50 \%$ de los auditores internos y personal técnico consultado opinan que existe un programa de educación continua en su UAI.

\section{RECOMENDACIONES}

Las recomendaciones para cada una de las variables son las siguientes:

\section{Metodología de las Unidades de Auditoría Interna para el aseguramiento de la calidad}

Indicadores de gestión

Se recomienda medir periódicamente la eficiencia y eficacia de la gestión de la UAI, mediante los indicadores de gestión. Esta sana práctica recomendada por el IIA Global garantizará un monitoreo de los indicadores de gestión de los procesos de planificación, ejecución, comunicación y seguimiento. De igual manera, los responsables de dirigir a las UAI tomarán decisiones para subsanar las deficiencias encontradas y establecer planes de mejora continua que le permitan a la UAI mejorar el desempeño y calidad de sus productos y servicios.

\section{Sistema de Aseguramiento de la Calidad}

Es recomendable mantener y mejorar el sistema de calidad de las UAI del sector público costarricense, el cual debe considerar la normativa nacional e internacional vigente. Por ejemplo, el Marco Internacional para la Práctica Profesional del IIA Global, las Directrices para la autoevaluación anual y la evaluación externa de calidad de las auditorías internas del Sector Público, D-2-2008-CO-DFOE; las NGASP y NEAI de la CGR (2014b), entre otras.

\section{Autoevaluación anual de calidad}

Con propósito de fortalecer las herramientas de trabajo de los auditores para la autoevaluación de la calidad y mejorar la gestión fiscalizadora de la UAI, se recomienda revisar las herramientas con una periodicidad anual, de manera tal que se incorporen temas de riesgo, formatos de papeles de trabajo, normas de calidad ISO y mejores prácticas internacionales, entre otros.

\section{Auditoría operativa}

La auditoría operativa influye en las actividades de la organización, debido a que sus recomendaciones generan múltiples decisiones en la alta gerencia. Por lo tanto, debe incluirse en el plan anual de trabajo de las UAI del sector público costarricense. La especialización de auditores 
operativos en las diferentes áreas de la institución permite generar más valor agregado a la gestión institucional.

\section{Presupuesto}

El presupuesto asignado a la UAI es una herramienta para la toma de decisiones del auditor interno. Su función fiscalizadora tiene asignados recursos materiales, humanos y tecnológicos, por lo tanto, debe planificar su gestión anual y estratégica con base en lo presupuestado. La UAI debe tener los recursos necesarios para la adecuada ejecución del plan anual de trabajo.

\section{Principios de la gestión de la calidad de la norma INTE/ISO 9000:2015}

Se recomienda incorporar en las actividades del proceso de auditoría los principios de la gestión de la calidad de la norma INTE/ISO 9001:2015, relacionados con el enfoque al cliente, liderazgo, compromiso de las personas, enfoque a procesos, mejora y toma de decisiones basada en la evidencia. Conforme lo establece la norma, la implementación de estos principios trae una serie de beneficios, por ejemplo, personal motivado, aumento de la eficacia y eficiencia, desarrollo y mejora de la capacidad, aumento de la confianza y colaboración en toda la entidad, mejora el desempeño del proceso, de las capacidades de la organización y de la satisfacción del cliente, mejora de los procesos de toma de decisiones e incremento de la reputación del ente.

\section{Sistema de gestión de la calidad INTE/ISO 9001:2015}

La adopción de un sistema de gestión de la calidad en una organización ayuda a mejorar su desempeño y genera mayor eficiencia, pero implica una erogación importante que no todas las instituciones públicas están dispuestas a desembolsar por asuntos presupuestarios. Sin embargo, es claro que implementar un sistema de gestión de la calidad basado en la norma INTE/ISO 9001:2015 trae beneficios, como organizar la documentación de los diferentes procesos de la institución, mejora el rendimiento del proceso, se espera un aumento en los usuarios del producto, mejor control de los documentos, entre otros.

\section{Aplicación del marco normativo y mejoras prácticas}

\section{Mejores prácticas mundiales en auditoría interna}

Es recomendable que la UAI incluya las mejores prácticas mundiales en la metodología para el aseguramiento de la calidad, con el fin de brindar al auditado un servicio y producto de calidad que agregue valor a los diferentes procesos de la organización y la sociedad costarricense.

\section{Herramientas tecnológicas}

Se recomienda la implementación de herramientas tecnológicas en la UAI, lo cual promueve beneficios para este departamento fiscalizador y que, paralelamente, mejoran el manejo de la organización, producto de las recomendaciones que se generan de los informes de la auditoría interna. El software de auditoría es una herramienta idónea para la UAI, genera datos en mayor volumen para el análisis y la toma de decisiones en las actividades del proceso de auditoría.

Aseguramiento de la calidad 
El aseguramiento de la calidad debe estar en el ADN de la UAI, para verificar que la gestión diaria cumpla con la normativa vigente que rige la profesión de auditoría y brindar al auditado un servicio y producto de calidad, que agregue valor. Al mismo tiempo, el usuario de la institución pública se beneficia con un mejor servicio.

\section{Auditoría Interna reinventada}

Las UAI deben reinventarse y aplicar mejores prácticas en su gestión diaria, que implique la generación de nuevas metodologías de trabajo, aplicando la normativa vigente, pero con la iniciativa de ir más allá de la revisión del control interno de la institución. Por ejemplo, la implementación de la auditoría continua, la planificación estratégica, los planes basados en riesgo y personal capacitado para cumplir sus funciones, entre otros.

\section{Análisis periódico de datos automatizados}

Se recomienda a las UAI incorporar en su plan anual de trabajo revisiones que incluyan el análisis periódico de datos automatizados, los cuales permitan efectuar evaluaciones de riesgos y controles para determinar oportunidades de mejora en la gestión diaria de la institución.

\section{Fortalezas y debilidades de las Unidades de Auditoría Interna}

\section{Fuerte respeto y credibilidad}

El fuerte respeto y credibilidad hacia los funcionarios de la UAI, por parte del jerarca y titulares subordinados, son requisitos fundamentales para la gestión fiscalizadora. Para ello es necesario que los auditados reciban productos y servicios con valor agregado, que impacten la gestión de la administración.

\section{Identificación de los riesgos de la institución}

Es sumamente importante y estratégica la identificación de los riesgos, pues permite a las UAI tomar decisiones y anticiparse a la administración en la detección oportuna de eventos, tales como inundaciones, riesgos tecnológicos, operativos, legales, liquidez, crédito, financieros, etc.

\section{Independencia y objetividad}

Conforme lo establece el marco normativo nacional e internacional, el personal de la UAI del sector público costarricense debe ejercer sus funciones con independencia y objetividad en las actividades del proceso de auditoría, relacionadas con la planificación, ejecución, comunicación y seguimiento.

\section{Recurso humano completo y calificado}

La UAI debe cuantificar los recursos requeridos para la adecuada ejecución del plan anual de trabajo y plan estratégico. La institución debe asignar los recursos a la auditoría interna para que pueda cumplir su función y su razón de ser. De igual forma, la UAI debe tener las herramientas 
necesarias para el desarrollo de cada una de las revisiones programadas en el plan anual de trabajo y para alcanzar calidad en su gestión.

\section{Universo auditable}

Para una adecuada gestión de la UAI, es fundamental disponer de recursos suficientes, por ejemplo, recursos humanos que realicen las labores de fiscalización y supervisión en cada una de las actividades del proceso de auditoría. Los recursos asignados para la adecuada gestión del plan anual de trabajo de la UAI deben ser utilizados eficientemente, en procura de brindar un servicio de calidad al auditado.

\section{Sistema de gestión automatizado}

Si bien el sistema de gestión automatizado tiene ventajas para la UAI y cualquier departamento, como el manejo de grandes volúmenes de datos, reducción del tiempo de trabajo, almacenamiento de la información, pues permite archivar gran volumen de datos en forma digital, así como la custodia de los papeles de trabajo, el auditor interno debe planificar una estrategia que abarque la fiscalización de las principales áreas de riesgo de la organización, con los recursos económicos, humanos y materiales que tiene disponibles.

\section{Capacitación profesional continua}

La UAI debe capacitar a su personal técnico colaborador en forma constante, para lo cual debe incorporar en sus actividades un cronograma anual de capacitación, que incluya las diferentes áreas que necesita reforzar el personal. Como parte de la capacitación permanente, puede incorporar las certificaciones profesionales internacionales, por ejemplo, la certificación Auditor Interno Certificado (CIA), Auditor Certificado de Sistemas Informáticos (CISA), COBIT, ITIL, ISO 27000, Certificado en Auditoría Gubernamental (CGAP), Certificado en Evaluación de Gestión de Riesgos (CRMA), etc.

Por último, es importante mencionar como limitación al alcance del estudio, que no existe un centro de datos de todas las UAI del sector público costarricense con información relevante de cada una, por ejemplo, informes de auditoría, oficios, reglamento de organización y funcionamiento, manuales y procedimientos, código de ética, cantidad de funcionarios, perfiles de esos funcionarios, entre otros datos; aspectos de gran importancia para fortalecer las limitaciones y carencias de la administración pública, con el propósito de fortalecer estrategias y mecanismos para el aseguramiento de la calidad. Adicionalmente, los resultados de la autoevaluación anual y evaluación externa de calidad de las auditorías internas no son remitidos a la CGR para su publicación, como sí se realiza con el índice de gestión institucional que se publica en la Memoria anual de la CGR (2018b).

\section{REFERENCIAS}

Asamblea Legislativa de la República de Costa Rica. (07 de setiembre de 1994). Ley 7428: Ley Orgánica de la Contraloría General de la República. La Gaceta, N. ${ }^{\circ} 210$. http://www.pgrweb. go.cr/scij/Busqueda/Normativa/Normas/nrm_texto_completo.aspx?param2=NRTC\&nValor1= $1 \&$ nValor2=21629\&strTipM=TC 
Asamblea Legislativa de la República de Costa Rica. (31 de julio de 2002). Ley 8292: Ley General de Control Interno. La Gaceta, N. ${ }^{o}$ 169. http://www.pgrweb.go.cr/scij/Busqueda/Normativa/ Normas/nrm_texto_completo.aspx?param1=NRTC\&nValorl=1\&nValor2=49185\&nValor3=52 569\&strTipM=TC

Bustamante Sánchez, C. (2014). Diseño de un plan de auditoría de gestión basada en riesgos para mejorar los procesos productivos de la empresa azucarera agroindustrial POMALCA S.A.A de la ciudad de Chilayo-2014 [Tesis para optar el título de Contador Público, Universidad Católica de Toribio de Mogrovejo]. Repositorio de tesis USAT.

http://hdl.handle.net/20.500.12423/187

Castro López, C. R., Martínez de Torres, A. M. \& Torres Gómez, R. A. (2015). Aseguramiento de la calidad del trabajo de auditoría factor relevante para la continuidad y progreso de las firmas de auditoría [Tesis de Licenciatura, Universidad de El Salvador]. Repositorio Institucional de la Universidad de El Salvador. http://ri.ues.edu.sv/id/eprint/8456/

Chavarría Barrantes, R., Collado Menéndez, H. \& Solano Cruz, G. (1997). Guía de auditoría para proyectos de inversión ejecutados por entidades beneficiarias de asistencia financiera [Tesis de Licenciatura, Universidad de Costa Rica], San José, Costa Rica.

Contraloría General de la República. (2004). Manual de normas para el ejercicio de la auditoría interna en el sector público M-1-2004-CO-DDI [derogado mediante resolución $\mathrm{N}^{\circ} \mathrm{R}-\mathrm{DC}-119$ del 16-12-2009. San José, Costa Rica]. La Gaceta N ${ }^{\circ} 246$ del 16 de diciembre de 2004.

Contraloría General de la República. (2007). Directrices para la Autoevaluación Anual de calidad de las Auditorías Internas del Sector Público (D-2-2007-CO-DFOE) [Resolución R-CO-15-2007]. Recuperado de http://www.pgrweb.go.cr/scij/Busqueda/Normativa/Normas/nrm_texto_ completo.aspx?param1=NRTC\&nValor1=1\&nValor2=59714\&nValor3=66768\&strTipM=TC

Contraloría General de la República. (2008). Resolución R-CO-33-2008. Directrices para la autoevaluación anual y la evaluación externa de calidad de las auditorías internas del Sector Público, D-2-2008-CO-DFOE del 11 de julio de 2008. La Gaceta, N. ${ }^{0}$ 147. http://www.pgrweb. go.cr/scij/Busqueda/Normativa/Normas/nrm_texto_completo.aspx?param1=NRTC\&nValor1= $1 \&$ nValor2=63650\&nValor3=73302\&strTipM=TC

Contraloría General de la República. (2010). Resolución R-DC-119-2009. Normas para el ejercicio de la Auditoría Interna en el Sector Público. La Gaceta, N. 28.

Contraloría General de la República. (2014). Resolución R-DC-64-2014. Normas Generales de Auditoría para el Sector Público (NGASP). La Gaceta, N. ${ }^{\circ} 184$.

Contraloría General de la República. (2018a). Resolución R-CO-83-2018. Lineamientos sobre gestiones que involucran a la auditoría interna presentadas ante la Contraloría General de la República. La Gaceta, N. . 146. https://www.pgrweb.go.cr/scij/Busqueda/Normativa/Normas/ nrm_texto_completo.aspx?param1=NRTC\&nValor1=1\&nValor2=86990\&nValor3=113136\&str TipM=TC

Contraloría General de la República. (2018b). Memoria Anual 2017. https://www.cgr.go.cr/03documentos/publicaciones/memoria-anual/memoria-anual.html

Contraloría General de la República. (2018c). Manual de referencia para Auditorías Internas (MARPAI). San José, Costa Rica.

Hernández Sampieri, R., Fernández Collado, C. y Baptista Lucio, M. (2014). Metodología de la investigación ( $6^{\circ}$ ed.). McGraw Hill / Interamericana Editores.

Instituto de Auditores Internos. (2015). Auditoría Continua: Coordinar Auditoría Continua y Monitoreo para proveer Aseguramiento Continuo. https://docplayer.es/35418047-Auditoriacontinua-coordinar-auditoria-continua-y-monitoreo-para-proveer-aseguramiento-continuo. html 
Instituto de Auditores Internos. (2017). Normas Internacionales para el Ejercicio Profesional de la Auditoría Interna. https://na.theiia.org/translations/PublicDocuments/IPPF-Standards-2017Spanish.pdf

Instituto de Auditores Internos de Argentina y Federación Latinoamericana de Auditores Internos. (2017). Auditoría de Alto Vuelo. XXII Congreso Latinoamericano de Auditores Internos (CLAI 2017). Buenos Aires, Argentina.

Instituto de Auditores Internos de Brasil y Federación Latinoamericana de Auditores Internos. (2018). XXIII Congreso Latinoamericano de Auditoría Interna (CLAI 2018). Foz de Iguazú, Brasil.

Instituto de Auditores Internos de Chile A.G. y Federación Latinoamericana de Auditores Internos. (2015). Auditoría Interna: El Nuevo Pilar de la Alta Dirección. XX Congreso Latinoamericano de Auditores Internos (CLA 2015). Santiago de Chile.

Instituto de Auditores Internos de Costa Rica. (2014). FODA Departamento de Auditoría Interna. Recuperado de

https://studylib.es/doc/7746952/foda-departamento-de-auditor\%C3\%ADa-interna

Instituto de Auditores Internos de España. (2017). Marco Internacional para la Práctica Profesional de la Auditoría Interna [Guías de implementación Capítulo V]. Recuperado de https:// auditoresinternos.es/uploads/media_items/marco-2017-guias-de-implementacion.original.pdf

Instituto de Normas Técnicas de Costa Rica (INTECO). (2015). Sistemas de gestión de la calidad. Requisitos ( $5^{\circ}$ ed.). INTECO.

Martínez Fallas, L. (2015). Implementación de la Auditoría Continua automatizada mediante el uso de las herramientas tecnológicas caseware idea y caseware monitor [Tesis de Maestría, Universidad de Costa Rica], San José, Costa Rica.

Mendívil Escalante, V. M. (2010). Elementos de Auditoría (6º ed.). Editorial Cengage Learning.

Organización Internacional de Entidades Fiscalizadoras Superiores. (2008). Normas Internacionales de las Entidades Fiscalizadoras Superiores (ISSAI) $N^{\circ} 40$ Control de Calidad para la EFS. INTOSAI.

Paredes Soldevilla, J. (2014). Auditoría I. Centro de Aplicación Editorial Imprenta Unión de la Universidad Peruana Unión.

Pedwar Castillo, L. (2015). Auditoría Continua Tendencia Global de la Auditoría Interna. https:// docplayer.es/44247233-Auditoria-continua-tendencia-global-de-la-auditoria-interna.html

Pugliese, W. (mayo de 2017). Auditoría continua como soporte para los indicadores claves de riesgos, controles y procesos (KRI, KCI, KPI) [Memorias del congreso]. XXI Congreso Latinoamericano de Auditoría Interna y Evaluación de Riesgos (CLAIN), San José, Costa Rica. http://felaban.s3-website-us-west-2.amazonaws.com/memorias/archivo20170530173852PM. pdf

Sandoval Morales, H. (2012). Introducción a la auditoría. Red Tercer Milenio. http://www.aliat.org. $\mathrm{mx} /$ BibliotecasDigitales/economico_administrativo/Introduccion_a_la_auditoria.pdf 
VII. ANEXOS

\section{ANEXO 1 \\ PERCEPCIÓN DEL AUDITOR INTERNO: VARIABLE METODOLOGÍA DE LA UAI PARA EL ASEGURAMIENTO DE LA CALIDAD}

\begin{tabular}{|c|c|c|c|c|c|c|c|c|}
\hline \multirow[b]{2}{*}{ Pregunta } & \multicolumn{2}{|c|}{ Siempre } & \multicolumn{2}{|c|}{ Algunas veces } & \multicolumn{2}{|c|}{ Nunca } & \multicolumn{2}{|c|}{ Total } \\
\hline & Absoluto & Relativo & Absoluto & Relativo & Absoluto & Relativo & Absoluto & Relativo \\
\hline 1 & 13 & $76.47 \%$ & 2 & $11.76 \%$ & 2 & $11.76 \%$ & 17 & $100.00 \%$ \\
\hline 2 & 10 & $58.82 \%$ & 5 & $29.41 \%$ & 2 & $11.76 \%$ & 17 & $100.00 \%$ \\
\hline 3 & 15 & $88.24 \%$ & 0 & $0.00 \%$ & 2 & $11.76 \%$ & 17 & $100.00 \%$ \\
\hline 4 & 10 & $58.82 \%$ & 3 & $17.65 \%$ & 4 & $23.53 \%$ & 17 & $100.00 \%$ \\
\hline 5 & 11 & $64.71 \%$ & 6 & $35.29 \%$ & 0 & $0.00 \%$ & 17 & $100.00 \%$ \\
\hline 6 & 14 & $82.35 \%$ & 3 & $17.65 \%$ & 0 & $0.00 \%$ & 17 & $100.00 \%$ \\
\hline 7 & 12 & $70.59 \%$ & 3 & $17.65 \%$ & 2 & $11.76 \%$ & 17 & $100.00 \%$ \\
\hline 8 & 14 & $82.35 \%$ & 2 & $11.76 \%$ & 1 & $5.88 \%$ & 17 & $100.00 \%$ \\
\hline 9 & 15 & $88.24 \%$ & 1 & $5.88 \%$ & 1 & $5.88 \%$ & 17 & $100.00 \%$ \\
\hline 10 & 4 & $23.53 \%$ & 6 & $35.29 \%$ & 7 & $41.18 \%$ & 17 & $100.00 \%$ \\
\hline 11 & 14 & $82.35 \%$ & 1 & $5.88 \%$ & 2 & $11.76 \%$ & 17 & $100.00 \%$ \\
\hline 12 & 14 & $82.35 \%$ & 2 & $11.76 \%$ & 1 & $5.88 \%$ & 17 & $100.00 \%$ \\
\hline 13 & 9 & $52.94 \%$ & 6 & $35.29 \%$ & 2 & $11.76 \%$ & 17 & $100.00 \%$ \\
\hline 14 & 13 & $76.47 \%$ & 4 & $23.53 \%$ & 0 & $0.00 \%$ & 17 & $100.00 \%$ \\
\hline 15 & 9 & $52.94 \%$ & 6 & $35.29 \%$ & 2 & $11.76 \%$ & 17 & $100.00 \%$ \\
\hline 16 & 12 & $70.59 \%$ & 3 & $17.65 \%$ & 2 & $11.76 \%$ & 17 & $100.00 \%$ \\
\hline 17 & 14 & $82.35 \%$ & 2 & $11.76 \%$ & 1 & $5.88 \%$ & 17 & $100.00 \%$ \\
\hline 18 & 6 & $35.29 \%$ & 4 & $23.53 \%$ & 7 & $41.18 \%$ & 17 & $100.00 \%$ \\
\hline 19 & 7 & $41.18 \%$ & 4 & $23.53 \%$ & 6 & $35.29 \%$ & 17 & $100.00 \%$ \\
\hline 20 & 5 & $29.41 \%$ & 4 & $23.53 \%$ & 8 & $47.06 \%$ & 17 & $100.00 \%$ \\
\hline 21 & 5 & $29.41 \%$ & 4 & $23.53 \%$ & 8 & $47.06 \%$ & 17 & $100.00 \%$ \\
\hline
\end{tabular}

Fuente: Elaboración propia con información proporcionada por los auditores internos del sector público costarricense, 2018. 


\section{PERCEPCIÓN DEL PERSONAL DE AUDITORÍA INTERNA: VARIABLE METODOLOGÍA DE LA UAI PARA EL ASEGURAMIENTO DE LA CALIDAD}

\begin{tabular}{|c|c|c|c|c|c|c|c|c|}
\hline \multirow[b]{2}{*}{ Pregunta } & \multicolumn{2}{|c|}{ Siempre } & \multicolumn{2}{|c|}{ Algunas veces } & \multicolumn{2}{|c|}{ Nunca } & \multicolumn{2}{|c|}{ Total } \\
\hline & Absoluto & Relativo & Absoluto & Relativo & Absoluto & Relativo & Absoluto & Relativo \\
\hline 1 & 84 & $94.38 \%$ & 4 & $4.49 \%$ & 1 & $1.12 \%$ & 89 & $100.00 \%$ \\
\hline 2 & 70 & $78.65 \%$ & 17 & $19.10 \%$ & 2 & $2.25 \%$ & 89 & $100.00 \%$ \\
\hline 3 & 70 & $78.65 \%$ & 16 & $17.98 \%$ & 3 & $3.37 \%$ & 89 & $100.00 \%$ \\
\hline 4 & 72 & $80.90 \%$ & 13 & $14.61 \%$ & 4 & $4.49 \%$ & 89 & $100.00 \%$ \\
\hline 5 & 75 & $84.27 \%$ & 12 & $13.48 \%$ & 2 & $2.25 \%$ & 89 & $100.00 \%$ \\
\hline 6 & 75 & $84.27 \%$ & 14 & $15.73 \%$ & 0 & $0.00 \%$ & 89 & $100.00 \%$ \\
\hline 7 & 70 & $78.65 \%$ & 17 & $19.10 \%$ & 2 & $2.25 \%$ & 89 & $100.00 \%$ \\
\hline 8 & 84 & $94.38 \%$ & 4 & $4.49 \%$ & 1 & $1.12 \%$ & 89 & $100.00 \%$ \\
\hline 9 & 87 & $97.75 \%$ & 1 & $1.12 \%$ & 1 & $1.12 \%$ & 89 & $100.00 \%$ \\
\hline 10 & 55 & $61.80 \%$ & 21 & $23.60 \%$ & 13 & $14.61 \%$ & 89 & $100.00 \%$ \\
\hline 11 & 80 & $89.89 \%$ & 6 & $6.74 \%$ & 3 & $3.37 \%$ & 89 & $100.00 \%$ \\
\hline 12 & 64 & $71.91 \%$ & 23 & $25.84 \%$ & 2 & $2.25 \%$ & 89 & $100.00 \%$ \\
\hline 13 & 56 & $62.92 \%$ & 27 & $30.34 \%$ & 6 & $6.74 \%$ & 89 & $100.00 \%$ \\
\hline 14 & 70 & $78.65 \%$ & 19 & $21.35 \%$ & 0 & $0.00 \%$ & 89 & $100.00 \%$ \\
\hline 15 & 63 & $70.79 \%$ & 25 & $28.09 \%$ & 1 & $1.12 \%$ & 89 & $100.00 \%$ \\
\hline 16 & 83 & $93.26 \%$ & 3 & $3.37 \%$ & 3 & $3.37 \%$ & 89 & $100.00 \%$ \\
\hline 17 & 78 & $87.64 \%$ & 10 & $11.24 \%$ & 1 & $1.12 \%$ & 89 & $100.00 \%$ \\
\hline 18 & 56 & $62.92 \%$ & 24 & $26.97 \%$ & 9 & $10.11 \%$ & 89 & $100.00 \%$ \\
\hline 19 & 56 & $62.92 \%$ & 25 & $28.09 \%$ & 8 & $8.99 \%$ & 89 & $100.00 \%$ \\
\hline 20 & 38 & $42.70 \%$ & 26 & $29.21 \%$ & 25 & $28.09 \%$ & 89 & $100.00 \%$ \\
\hline 21 & 37 & $41.57 \%$ & 20 & $22.47 \%$ & 32 & $35.96 \%$ & 89 & $100.00 \%$ \\
\hline
\end{tabular}

Fuente: elaboración propia con información proporcionada por el personal de la UAI del sector público costarricense, 2018. 


\section{PERCEPCIÓN DEL AUDITOR INTERNO: VARIABLE APLICACIÓN DEL MARCO NORMATIVO Y MEJORES PRÁCTICAS}

\begin{tabular}{lcccccccc}
\hline & \multicolumn{2}{c}{ Siempre } & \multicolumn{2}{c}{ Algunas veces } & \multicolumn{2}{c}{ Nunca } & \multicolumn{2}{c}{ Total } \\
\hline Pregunta & Absoluto & Relativo & Absoluto & Relativo & Absoluto & Relativo & Absoluto & Relativo \\
\hline 22 & 15 & $88.24 \%$ & 2 & $11.76 \%$ & 0 & $0.00 \%$ & 17 & $100.00 \%$ \\
23 & 16 & $94.12 \%$ & 1 & $5.88 \%$ & 0 & $0.00 \%$ & 17 & $100.00 \%$ \\
24 & 14 & $82.35 \%$ & 2 & $11.76 \%$ & 1 & $5.88 \%$ & 17 & $100.00 \%$ \\
25 & 16 & $94.12 \%$ & 1 & $5.88 \%$ & 0 & $0.00 \%$ & 17 & $100.00 \%$ \\
26 & 16 & $94.12 \%$ & 0 & $0.00 \%$ & 1 & $5.88 \%$ & 17 & $100.00 \%$ \\
27 & 17 & $100.00 \%$ & 0 & $0.00 \%$ & 0 & $0.00 \%$ & 17 & $100.00 \%$ \\
28 & 14 & $82.35 \%$ & 3 & $17.65 \%$ & 0 & $0.00 \%$ & 17 & $100.00 \%$ \\
29 & 14 & $82.35 \%$ & 2 & $11.76 \%$ & 1 & $5.88 \%$ & 17 & $100.00 \%$ \\
30 & 15 & $88.24 \%$ & 2 & $11.76 \%$ & 0 & $0.00 \%$ & 17 & $100.00 \%$ \\
31 & 10 & $58.82 \%$ & 6 & $35.29 \%$ & 1 & $5.88 \%$ & 17 & $100.00 \%$ \\
32 & 6 & $35.29 \%$ & 9 & $52.94 \%$ & 2 & $11.76 \%$ & 17 & $100.00 \%$ \\
33 & 9 & $52.94 \%$ & 1 & $5.88 \%$ & 7 & $41.18 \%$ & 17 & $100.00 \%$ \\
34 & 12 & $70.59 \%$ & 4 & $23.53 \%$ & 1 & $5.88 \%$ & 17 & $100.00 \%$ \\
35 & 9 & $52.94 \%$ & 5 & $29.41 \%$ & 3 & $17.65 \%$ & 17 & $100.00 \%$ \\
36 & 8 & $47.06 \%$ & 6 & $35.29 \%$ & 3 & $17.65 \%$ & 17 & $100.00 \%$ \\
37 & 9 & $52.94 \%$ & 4 & $23.53 \%$ & 4 & $23.53 \%$ & 17 & $100.00 \%$ \\
\hline
\end{tabular}

Fuente: elaboración propia con información proporcionada por los auditores internos del sector público costarricense, 2018. 


\section{ANEXO 4 \\ PERCEPCIÓN DEL PERSONAL DE AUDITORÍA INTERNA: VARIABLE APLICACIÓN DEL MARCO NORMATIVO Y MEJORES PRÁCTICAS}

\begin{tabular}{lcccccccc}
\hline & \multicolumn{2}{c}{ Siempre } & \multicolumn{2}{c}{ Algunas veces } & \multicolumn{2}{c}{ Nunca } & \multicolumn{2}{c}{ Total } \\
\hline Pregunta & Absoluto & Relativo & Absoluto & Relativo & Absoluto & Relativo & Absoluto & Relativo \\
\hline 22 & 87 & $97.75 \%$ & 2 & $2.25 \%$ & 0 & $0.00 \%$ & 89 & $100.00 \%$ \\
23 & 86 & $96.63 \%$ & 3 & $3.37 \%$ & 0 & $0.00 \%$ & 89 & $100.00 \%$ \\
24 & 87 & $97.75 \%$ & 2 & $2.25 \%$ & 0 & $0.00 \%$ & 89 & $100.00 \%$ \\
25 & 87 & $97.75 \%$ & 2 & $2.25 \%$ & 0 & $0.00 \%$ & 89 & $100.00 \%$ \\
26 & 84 & $94.38 \%$ & 3 & $3.37 \%$ & 2 & $2.25 \%$ & 89 & $100.00 \%$ \\
27 & 80 & $89.89 \%$ & 9 & $10.11 \%$ & 0 & $0.00 \%$ & 89 & $100.00 \%$ \\
28 & 77 & $86.52 \%$ & 12 & $13.48 \%$ & 0 & $0.00 \%$ & 89 & $100.00 \%$ \\
29 & 80 & $89.89 \%$ & 7 & $7.87 \%$ & 2 & $2.25 \%$ & 89 & $100.00 \%$ \\
30 & 84 & $94.38 \%$ & 5 & $5.62 \%$ & 0 & $0.00 \%$ & 89 & $100.00 \%$ \\
31 & 75 & $84.27 \%$ & 10 & $11.24 \%$ & 4 & $4.49 \%$ & 89 & $100.00 \%$ \\
32 & 49 & $55.06 \%$ & 35 & $39.33 \%$ & 5 & $5.62 \%$ & 89 & $100.00 \%$ \\
33 & 68 & $76.40 \%$ & 19 & $21.35 \%$ & 2 & $2.25 \%$ & 89 & $100.00 \%$ \\
34 & 71 & $79.78 \%$ & 18 & $20.22 \%$ & 0 & $0.00 \%$ & 89 & $100.00 \%$ \\
35 & 64 & $71.91 \%$ & 21 & $23.60 \%$ & 4 & $4.49 \%$ & 89 & $100.00 \%$ \\
36 & 56 & $62.92 \%$ & 28 & $31.46 \%$ & 5 & $5.62 \%$ & 89 & $100.00 \%$ \\
37 & 63 & $70.79 \%$ & 23 & $25.84 \%$ & 3 & $3.37 \%$ & 89 & $100.00 \%$ \\
\hline
\end{tabular}

Fuente: elaboración propia con información proporcionada por los auditores internos del sector público costarricense, 2018.

ANEXO 5

PERCEPCIÓN DEL AUDITOR INTERNO: VARIABLE FORTALEZAS Y DEBILIDADES DE LAS UAI

\begin{tabular}{lcccccccc}
\hline & \multicolumn{2}{c}{ Siempre } & \multicolumn{2}{c}{ Algunas veces } & \multicolumn{2}{c}{ Nunca } & \multicolumn{2}{c}{ Total } \\
\hline Pregunta & Absoluto & Relativo & Absoluto & Relativo & Absoluto & Relativo & Absoluto & Relativo \\
\hline 38 & 11 & $64.71 \%$ & 4 & $23.53 \%$ & 2 & $11.76 \%$ & 17 & $100.00 \%$ \\
39 & 11 & $64.71 \%$ & 5 & $29.41 \%$ & 1 & $5.88 \%$ & 17 & $100.00 \%$ \\
40 & 17 & $100.00 \%$ & 0 & $0.00 \%$ & 0 & $0.00 \%$ & 17 & $100.00 \%$ \\
41 & 7 & $41.18 \%$ & 7 & $41.18 \%$ & 3 & $17.65 \%$ & 17 & $100.00 \%$ \\
42 & 5 & $29.41 \%$ & 6 & $35.29 \%$ & 6 & $35.29 \%$ & 17 & $100.00 \%$ \\
43 & 7 & $41.18 \%$ & 3 & $17.65 \%$ & 7 & $41.18 \%$ & 17 & $100.00 \%$ \\
44 & 9 & $52.94 \%$ & 4 & $23.53 \%$ & 4 & $23.53 \%$ & 17 & $100.00 \%$ \\
\hline
\end{tabular}

Fuente: elaboración propia con información proporcionada por los auditores internos del sector público costarricense, 2018. 


\section{ANEXO 6 \\ PERCEPCIÓN DEL PERSONAL DE LA AUDITORÍA INTERNA: VARIABLE FORTALEZAS Y DEBILIDADES DE LAS UAI}

\begin{tabular}{lcccccccc}
\hline & \multicolumn{2}{c}{ Siempre } & \multicolumn{2}{c}{ Algunas veces } & \multicolumn{2}{c}{ Nunca } & \multicolumn{2}{c}{ Total } \\
\hline Pregunta & Absoluto & Relativo & Absoluto & Relativo & Absoluto & Relativo & Absoluto & Relativo \\
\hline 38 & 58 & $65.17 \%$ & 31 & $34.83 \%$ & 0 & $0.00 \%$ & 89 & $100.00 \%$ \\
39 & 72 & $80.90 \%$ & 17 & $19.10 \%$ & 0 & $0.00 \%$ & 89 & $100.00 \%$ \\
40 & 84 & $94.38 \%$ & 5 & $5.62 \%$ & 0 & $0.00 \%$ & 89 & $100.00 \%$ \\
41 & 63 & $70.79 \%$ & 26 & $29.21 \%$ & 0 & $0.00 \%$ & 89 & $100.00 \%$ \\
42 & 59 & $66.29 \%$ & 29 & $32.58 \%$ & 1 & $1.12 \%$ & 89 & $100.00 \%$ \\
43 & 76 & $85.39 \%$ & 8 & $8.99 \%$ & 5 & $5.62 \%$ & 89 & $100.00 \%$ \\
44 & 54 & $60.67 \%$ & 33 & $37.08 \%$ & 2 & $2.25 \%$ & 89 & $100.00 \%$ \\
\hline
\end{tabular}

Fuente: elaboración propia con información proporcionada por el personal técnico colaborador de la UAI del sector público costarricense, 2018. 